\title{
Melting and Solidification Enhancement Using a Combined Heat Pipe, Foil
}

\section{Approach}

\author{
Nourouddin Sharifi ${ }^{\mathrm{a}}$ \\ Theodore L. Bergman ${ }^{b^{*}}$ \\ Michael J. Allen ${ }^{\mathrm{a}}$ \\ Amir Faghri ${ }^{\text {a }}$
}

${ }^{a}$ Department of Mechanical Engineering, University of Connecticut, 191 Auditorium Road, Storrs, CT 06269-3139, USA

${ }^{\mathrm{b}}$ Department of Mechanical Engineering, University of Kansas,

Lawrence, KS 66045, USA

*Corresponding Author

Theodore L. Bergman

tlbergman@ku.edu

Ph: +1 7858643181 


\begin{abstract}
Melting and solidification of a phase change material is investigated, experimentally and computationally, using a novel heat pipe - metal foil approach. By embedding a PCM within a metal foil matrix, and delivering (or extracting) thermal energy to (or from) the matrix with a vertically-oriented heat pipe, overall thermal resistances between a working fluid and the PCM solid-liquid interface can be reduced. This leads to increased phase change rates relative to configurations involving only the heat pipe, or only a solid rod of the same physical dimensions as the heat pipe. For a small (approximately 1 percent) volume fraction of foil in the PCM - foil matrix, measured and predicted melting (solidification) rates associated with heat pipe - foil configurations are increased by approximately 300 percent (900 percent) relative to configurations involving the rod with no foil. Melting and solidification rates relative to configurations involving the heat pipe with no foil, are increased by approximately 200 percent and 600 percent. The influence of the heat pipe evaporator-to-condenser length ratio, as well as the overall temperature difference between the working fluid and the PCM fusion temperature, is also reported.
\end{abstract}

Keywords: Melting, solidification, latent heat thermal energy storage, heat pipe, foil 


\begin{tabular}{|c|c|}
\hline \multicolumn{2}{|c|}{ Nomenclature } \\
\hline acc & accuracy \\
\hline$c_{p}$ & specific heat at constant pressure $(\mathrm{J} / \mathrm{kg} \cdot \mathrm{K})$ \\
\hline$D$ & diameter $(m)$ \\
\hline$f_{f}$ & foil volume fraction \\
\hline$f_{\ell}$ & volumetric liquid fraction \\
\hline$g$ & gravitational acceleration $\left(\mathrm{m} / \mathrm{s}^{2}\right)$ \\
\hline$h_{f g}$ & latent heat of vaporization $(\mathrm{kJ} / \mathrm{kg})$ \\
\hline$h_{s \ell}$ & latent heat of fusion $(\mathrm{kJ} / \mathrm{kg})$ \\
\hline HP & heat pipe \\
\hline HTF & heat transfer fluid \\
\hline$k$ & thermal conductivity $(\mathrm{W} / \mathrm{m} \cdot \mathrm{K})$ \\
\hline$L$ & length (m) \\
\hline$m$ & mass $(\mathrm{kg})$ \\
\hline$p$ & pressure $(\mathrm{Pa})$ \\
\hline$r, z$ & coordinate directions $(\mathrm{m})$ \\
\hline$R$ & gas constant $(\mathrm{J} / \mathrm{kg} \cdot \mathrm{K})$ \\
\hline res & resolution \\
\hline$t$ & time (s or min), thickness (m) \\
\hline$T$ & temperature $(\mathrm{K})$, thermocouple \\
\hline$u$ & uncertainty \\
\hline$V$ & volume $\left(\mathrm{m}^{3}\right)$ \\
\hline
\end{tabular}




$\begin{array}{ll}\text { Greek } & \\ \beta & \text { thermal expansion coefficient }\left(\mathrm{K}^{-1}\right) \\ \varepsilon & \text { effectiveness } \\ \mu & \text { dynamic viscosity }(\mathrm{Pa} \cdot \mathrm{s}) \\ \rho & \text { density }\left(\mathrm{kg} / \mathrm{m}^{3}\right)\end{array}$

Subscripts

$\begin{array}{ll}a & \text { adiabatic } \\ \text { air } & \text { air } \\ b & \text { bottom } \\ c v & \text { control volume } \\ e & \text { enclosure } \\ \text { eff } & \text { effective } \\ f & \text { foil } \\ g & \text { gap } \\ h p & \text { heat pipe } \\ h t f & \text { heat transfer fluid } \\ i & \text { inner, initial } \\ \text { in } & \text { inlet } \\ \ell & \text { liquid phase of PCM } \\ m & \text { melting } \\ o & \text { outer } \\ \text { out } & \text { outlet }\end{array}$




$\begin{array}{ll}\text { PCM } & \text { phase change material } \\ r, z & \text { coordinate directions } \\ r e f & \text { reference } \\ \text { rod } & \text { rod } \\ s & \text { solid phase of PCM, solidification } \\ \text { sat } & \text { saturation } \\ t & \text { top } \\ v & \text { vapor phase of heat pipe working fluid } \\ w & \text { wall }\end{array}$




\section{Introduction}

Latent heat thermal energy storage (LHTES) is considered to be more advantageous than sensible TES for many applications because of its high energy density [1 - 6]. Also, because of the nature of phase change, the energy storage and delivery can occur with minimal temperature differences within a LHTES system. However, the low thermal conductivity of most inexpensive phase change materials (PCMs) is a drawback, potentially limiting the heat transfer rates within, and phase change rates of the PCM.

Various strategies to overcome the large PCM thermal resistance have been proposed, including but not limited to use of high thermal conductivity porous matrices filled with PCM $[7,8]$, dispersion of high thermal conductivity particles within the PCM $[9,10]$, micro-encapsulation of the PCM $[11,12]$, use of extended surfaces $[13-19]$, and use of heat pipes (HPs) which are capable of passively transferring large amounts of heat efficiently over considerable distances through small cross-sectional areas [20].

\subsection{Heat pipe-assisted phase change (HP-PCM)}

Two patents involving the integration of HPs with PCMs are held by Faghri [21, 22]. In related research, Horbaniuc et al. [23] analytically investigated the solidification of PCM surrounding a longitudinally-finned HP. It was shown that, as expected, addition of more fins to the HP increases PCM solidification rates. Similarly, incorporation of a HP heat exchanger in a LHTES system was investigated experimentally by Liu et al. [24] in which a circumferentially-finned, acetone-charged copper thermosyphon was considered, with stearic acid as the PCM. Water was the heat transfer fluid (HTF) used to, ultimately, 
melt or solidify the PCM. The influence of the HTF inlet temperature and the HTF mass flow rate on the heat transfer and phase change rates was of particular interest.

Motivated by applications involving concentrating solar power, Shabgard et al. [25] developed a thermal network model to simulate both charging (melting) and discharging (solidification) a high temperature LHTES system. Multiple HPs were positioned between the HTF and PCM in two distinct geometrical configurations; one with PCM surrounding a tube through which flowed HTF, and the other involving PCM housed inside a tube across which the HTF flowed. The HPs increased the heat transfer rates to and from the PCM, and the improvement in phase change rates was quantified in terms of an effectiveness. The benefits associated with exploiting HP-assistance for LHTES were experimentally confirmed by Robak et al. [26] using an apparatus that consisted of a vertical cylindrical enclosure filled with n-octadecane. HPs were inserted between the HTF and the PCM, providing an effective thermal pathway to drive phase change. The measured thermal performance with HPs was compared to cases without HPs (i.e., transferring heat between the PCM and HTF through a plane wall) and again quantified in terms of an effectiveness. Melting rates for the HP configuration were approximately $60 \%$ higher than for the non-HP case, while solidification rates were approximately doubled relative to the plane wall case. The detailed numerical investigation of Sharifi et al. [27] provided additional insight into the heat transfer mechanisms responsible for the impressive thermal performance of the HP-PCM concept.

\subsection{Foil-assisted phase change (Foil-PCM)}


Melting and solidification rates can also be increased by adding high-thermalconductivity material, such as metal foil, to a PCM. A representative numerical study considered the effect of integrating thin aluminum foils, arranged orthogonally with respect to the axis of a steam tube, within a PCM [28]. The $\mathrm{PCM}\left(\mathrm{a} \mathrm{KNO}_{3} / \mathrm{NaNO}_{3}\right.$ eutectic mixture) filled the spaces between individual foils, as well as between the foils and the tube. Predictions showed that the solidification time could be decreased by approximately $25 \%$ by either increasing the foil thickness or decreasing the foil pitch. In related work, Bayón et al. [29] experimentally tested a high temperature LHTES system charged by steam flowing from a parabolic-trough solar collector. Expanded graphite foils were arranged on tubes in a sandwich configuration to increase the effective thermal conductivity of the PCM. The temporal variation of the outlet steam quality, along with the corresponding $\mathrm{PCM}$ (a $\mathrm{KNO}_{3} / \mathrm{NaNO}_{3}$ eutectic mixture) temperature-time behavior showed that the complete charging time could be reduced significantly by incorporating the foils with the PCM. In a similar study, Sugawara et al. [30] investigated freezing of water around a horizontal copper tube, through which flowed a cold HTF. Copper foils of thickness $0.03 \mathrm{~mm}$ were positioned around the tube to increase the freezing rate. It was found that by using only 0.025 foil volume fraction, the solidification rate could be increased by a factor of four, relative to the case without foils.

In addition to increasing phase change rates for LHTES systems involving a HTF, use of foils offers other advantages relative to, for example, conventional finned heat transfer surfaces. First, foils are typically flexible because of their relatively small thickness compared to fins (or the interconnecting solid structures of metal porous foams) which are rigid. Structural flexibility is desirable, in that it can minimize the propensity 
for material damage or failure associated with the expansion and contraction of the PCM upon phase change, especially in high temperature applications where the metal itself may undergo considerable expansion from its initial cool state. Also, as will become evident, foils do not need to be physically attached to heat transfer surfaces by welding or fusion in order to increase, significantly, the thermal performance of a HTF-LHTES system. Finally, foils are typically inexpensive relative to conventional fins or metallic porous materials, in terms of both raw material and manufacturing costs.

Building on literature that has quantified the benefits of both (i) the HP-PCM and (ii) the Foil-PCM approaches, a novel concept (HP-Foil-PCM) is presented here that involves the integration of HPs with foils as a means to enhance the thermal performance of LHTES systems. The objective is to experimentally and analytically determine the thermal performance of the HP-Foil-PCM concept.

\section{Experimental apparatus}

As shown in Fig. 1, a PCM is contained within an upright cylindrical enclosure that is formed by an acrylic tube of $D_{e, i}=41 \mathrm{~mm}$ inner diameter, $L_{e}=125 \mathrm{~mm}$ height, and 4.6 $\mathrm{mm}$ wall thickness. The bottom of the enclosure consists of a $5 \mathrm{~mm}$ thick acrylic disk of $50.2 \mathrm{~mm}$ diameter, while the top of the enclosure is a $10 \mathrm{~mm}$ thick aluminum plate. A compartment of air overlies the PCM to allow for (i) PCM expansion and, as will become evident, (ii) measurement of the instantaneous PCM solid or liquid fraction. The enclosure is made air-tight by sealing the interfaces with synthetic O-rings, both of which are compressed by the all-threaded yoke structure. 
A centrally-located, $L_{h p}=175 \mathrm{~mm}$ long, $D_{h p}=6 \mathrm{~mm}$ outer diameter, copper-water HP (Enertron, model HP-HD06DI17500BA) penetrates the bottom of the enclosure. The HP bottom and adiabatic sections (of lengths $L_{b}+L_{a}$, respectively) are located within an underlying heat exchanger, while the HP top section (of length $L_{t}$ ) is in the PCM. During solidification, the HP bottom section serves as the HP condenser, while evaporation of the HP working fluid occurs in the HP top section. During PCM melting, evaporation (condensation) occurs in the bottom (top) HP section. The HP is secured in place by silicone adhesive, which also ensures an air-tight seal.

Heat is supplied to, or extracted from, the bottom section of the HP by a HTF (water) flowing in a heat exchanger formed of five $10 \mathrm{~mm}$ thick welded aluminum plates, and an overlying acrylic plate of thickness $3 \mathrm{~mm}$. The heat exchanger has overall dimensions of $140 \mathrm{~mm}$ (length) $\times 100 \mathrm{~mm}$ (width) $\times 102 \mathrm{~mm}$ (height). To thermally isolate the PCM from the HTF (except through the thermal pathway provided by the HP), an air gap of 2 $\mathrm{mm}$ thickness separates the upper acrylic plate of the heat exchanger from the bottom acrylic disk of the PCM enclosure. In addition, air that is trapped in the uppermost $20 \mathrm{~mm}$ of the heat exchanger is not bled from the system, providing an additional thermal resistance between the HTF and the PCM. Lauda RM5 circulators were used to control the HTF temperature.

Prior to adding PCM (99\% pure n-octadecane with a melting temperature of $T_{m} \approx$ $28^{\circ} \mathrm{C}$ ) to the enclosure, aluminum foils of thickness $0.017 \mathrm{~mm}$, outer diameter of $D_{f, o}=$ $D_{e, i}-2 \mathrm{~mm}=39 \mathrm{~mm}$, and inner diameter $D_{f, i}=D_{h p}-2 \mathrm{~mm}=4 \mathrm{~mm}$ were press fitted along the top section of the HP (of length $L_{t}$ ). The installation method is sufficient to secure the foils in an approximately fixed location during phase change of the PCM. 
Once assembled, the entire apparatus was insulated with fiberglass batting ( $20 \mathrm{~mm}$ thick) held within a box constructed of $37 \mathrm{~mm}$ thick expanded polystyrene insulation. The thermophysical properties of the PCM and other components are listed in Table 1.

Local temperatures were measured with 15 Teflon-coated, $254 \mu \mathrm{m}$ diameter chromel-alumel (K-type) thermocouples, the locations of which are provided in Table 2, (except for $T_{14}$ and $T_{15}$, which were inserted in the heat exchanger inlet and outlet, respectively). The $r-z$ coordinate system is shown in Fig. 1. All of the thermocouples were fabricated from the same spools of wire to minimize bias error when measuring temperature differences, and were calibrated using the boiling and freezing points of distilled water to within an estimated uncertainty of $\pm 0.1^{\circ} \mathrm{C}$. The placement accuracy of the thermocouples, which were inserted through small holes drilled in the vertical wall of the acrylic cylinder that were subsequently sealed with silcone, is $\pm 1 \mathrm{~mm}$. Thermocouple voltages were collected using a National Instruments data acquisition (NI CDAQ-9172) system at 1 second intervals using LabVIEW software.

In addition to local temperatures, the instantaneous PCM liquid fraction was determined by monitoring the air pressure and temperature within the air-tight enclosure, using the procedure reported in Appendix A. As such, a pressure transducer (Sper Scientific, Model PS100 - 2BAR) was installed in the top enclosure plate. The output voltage from the transducer was collected (Sper Scientific, Model 840065) at $60 \mathrm{~s}$ intervals. Using the sequential perturbation method [31], the uncertainty in the measured liquid fraction can be estimated, as discussed in Appendix A. 


\section{Experimental procedure}

\subsection{PCM melting}

For the experiments involving melting, the PCM was first heated and de-gassed under vacuum. Once conditioned, a small amount of the molten PCM was poured into the enclosure, creating an initial liquid layer approximately $5 \mathrm{~mm}$ thick. The test cell was then shaken gently to remove, to the extent possible, air trapped between the individual foils. Subsequently, the heat transfer fluid, at $T_{h t, i n}=T_{14}=11^{\circ} \mathrm{C}$, was directed to the test cell to solidify the PCM layer, and the process was repeated until the desired total amount of PCM was added to the enclosure. After filling, the test cell was leveled, insulated, and allowed to equilibrate at room temperature for 12 hours.

Prior to the start of an experiment, the heat transfer fluid, at $T_{h t \text {, in }}=25^{\circ} \mathrm{C}$, was circulated in the heat exchanger for approximately one hour to increase the solid PCM temperature to approximately $25^{\circ} \mathrm{C}$. Subsequently, the HTF flow to the heat exchanger was curtailed, and the circulating bath temperature was increased to the experimental set point, $T_{h t f, i n}=T_{14}=45^{\circ} \mathrm{C}$. Once this temperature was achieved, the HTF was reintroduced to the heat exchanger, marking the start of an experiment. Each experiment was terminated when the PCM was completely melted, as determined by observing a constant air pressure. The mass of PCM used was approximately $0.09 \mathrm{~kg}, 0.08 \mathrm{~kg}$ or $0.072 \mathrm{~kg}$, corresponding to $L_{t}=90 \mathrm{~mm}, 80 \mathrm{~mm}$ or $72 \mathrm{~mm}$, respectively.

\subsection{PCM solidification}

Solidification experiments begin with liquid, de-gassed PCM within the enclosure. Warm HTF was circulated to bring the temperature of the liquid PCM to an initial value 
of approximately $31^{\circ} \mathrm{C}$. Once the measured PCM temperatures reached the desired value, a second chiller (Lauda, RM5), circulated the heat transfer fluid to the heat exchanger with $T_{h t f \text {,in }}=T_{14}=11^{\circ} \mathrm{C}$, marking the start of the experiment. Each solidification experiment was curtailed when the PCM solidified completely, as indicated by a constant measured air pressure.

Each experiment was conducted twice to ensure repeatability. Differences in the results of the two experiments were found to be minor with, for example, instantaneous liquid fractions in agreement to within 1 percentage point. The experimental results presented here correspond to the averaged measured values of the two experiments.

\section{Physical model}

A numerical model was developed to simulate the transient response of the conjugate system composed of the PCM and foils (or pure PCM without foils), the HP (or, a solid rod of the same dimensions as the HP), and the enclosure walls. For cases without foils, natural convection occurs in the PCM, and the mass, momentum and energy equations are solved using a transient, two-dimensional finite volume approach that incorporates the temperature-transforming model [32, 33]. For cases involving PCM and foils, both solidification and melting of the PCM are considered to be conductiondominated.

Several additional assumptions are made regarding the physical system. The exterior of the PCM enclosure, as well as the top and bottom ends of the HP (or the solid rod) are adiabatic. All thermophysical properties are assumed to be constant except for the density of the HP working fluid, which is considered to be an ideal gas experiencing two- 
dimensional, laminar, and compressible flow. The HP wick is assumed to be fully saturated, and the HP working fluid at the wick-vapor interface is assumed to be in its saturated state. Liquid flow in the HP wick is neglected [34] since a sufficient capillary pressure is assumed to be provided by the HP wick to drive the liquid in the wick, for the operating conditions presented here. The Boussinesq approximation is applied to the molten PCM, and natural convection is assumed to be two-dimensional, incompressible, and laminar. Thermal radiation is assumed to be negligible, as are thermal contact resistances.

\subsection{Computational domain}

The computational domain is shown in Fig. 2a. As evident, the HP is segmented into three radial regions: the vapor phase of the HP working fluid, the wick (of thickness 0.4 $\mathrm{mm}$ ), and the HP solid wall (of thickness $0.25 \mathrm{~mm}$ ). The annular space between the HP and interior enclosure wall (both of length $L_{t}$ ) is filled with the foil-PCM composite, or with pure PCM. The lower portion of the system consists of the HP adiabatic section (of length $L_{a}$ ) and the HP bottom section (of length $L_{b}$ ).

\subsection{Effective thermophysical properties}

The effective thermophysical properties of the HP wick are calculated by averaging the properties of the HP working fluid and copper wick shown in Table 1, yielding $k_{\text {eff }}=$ $201 \mathrm{~W} / \mathrm{m} \cdot \mathrm{K}$ and $\left(\rho c_{p}\right)_{e f f}=3803 \mathrm{~kJ} / \mathrm{m}^{3} \cdot \mathrm{K}[20]$.

The foil-PCM composite is considered to be an anisotropic PCM with distinct effective thermal conductivities in the radial and axial directions. Because of the foil 
dimensions, and the manner in which the foils are installed in the enclosure, care was taken to describe the effective properties in each of the three foil-PCM sub-regions described in Fig. 2b.

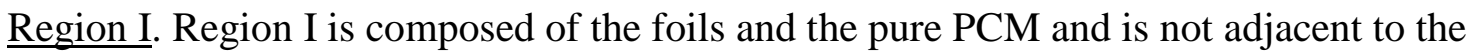
HP (or rod). Based upon the foil thickness and planar area, the number of foils, and the overall volume of Region I, the experimental foil volume fraction is calculated to be $f_{f}=$ 0.0121. The effective thermophysical properties are calculated based upon this foil volume fraction, using the thermophysical properties of Table 1, and are shown in Table 3. Specifically, the effective thermal conductivities in the radial and axial directions of Region I are determined by considering the foil and PCM thermal resistances to be in parallel and series, respectively [35].

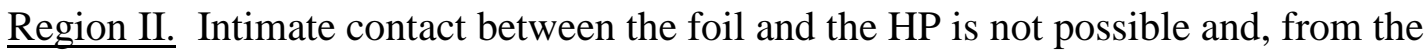
perspective of enhancing durability through multiple phase change cycles, is not desirable. Based upon microscopic inspection of the experimental apparatus, a gap usually exists between the foil and the HP, typically of width $0.0 \mathrm{~mm} \leq r_{g}-r_{h p} \leq 0.02 \mathrm{~mm}$. Based upon this inspection, a gap width of $0.01 \mathrm{~mm}$ is assumed. The radial dimension of the computational control volume adjacent to the exterior of the HP is $r_{c v}-r_{h p}=0.251 \mathrm{~mm}$. Using this as the radial dimension of a unit cell within Region II, and $\left(t_{p c m}+t_{f}\right) / 2$ as the cell's axial dimension, the unit cell consists of a LHS sub-region consisting of pure PCM (extending from $r_{h p}$ to $r_{g}=r_{h p}+0.01 \mathrm{~mm}$ ), a RHS sub-region consisting of pure foil (extending from $r=r_{g}$ to $r=r_{c v}$ ), and a second RHS sub-region consisting of pure PCM 
(also extending from $r=r_{g}$ to $r=r_{c v}$ ). Based on the foil thickness and pitch, as well as the gap between the HP and foil, the foil volume fraction in Region II is $f_{f}=0.0116$, yielding the effective densities, specific heats, and latent heats of fusion reported in Table 3. Radial conduction through the unit cell occurs through a lane consisting of pure PCM, and a second, parallel lane consisting of PCM and foil in series. Conduction in the axial direction occurs through a lane of pure PCM adjacent to the HP, and a second, parallel lane consisting of PCM and foil in series. The anisotropic nature of the foil-PCM composite is accounted for by the effective radial and axial thermal conductivities that are calculated using an equivalent resistance network approach [35] and are reported in Table 3.

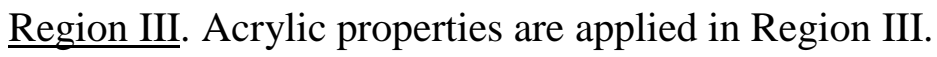

\subsection{Boundary and initial conditions}

A constant and uniform temperature, $T_{b}$, is applied along the vertical exterior of the HP bottom section. Radial gradients of temperature, pressure, and the axial velocity component, as well as the radial velocity component, are zero at $r=0$. The remaining external boundaries (including the top of the PCM and the HP at the same vertical location) are adiabatic. No-slip conditions are specified at all solid surfaces as well as at the top boundary of the domain. The entire domain is specified to be initially isothermal at $3^{\circ} \mathrm{C}$ below (above) the fusion temperature of the PCM for the melting (solidification) simulations.

\subsection{Numerical methodology}


Without the foil, natural convection occurs in the PCM during melting, and the governing mass, momentum and energy equations for both the HP and PCM are described in [27]. For cases involving foil, heat transfer within the foil-PCM composite is conduction-dominated, requiring solution of only the energy equation in the composite, using the effective thermophysical properties of Table 3. Preliminary simulations were performed using grid sizes up to $240 \times 120(z \times r)$, for a $L_{t}=90 \mathrm{~mm}, L_{b}=55 \mathrm{~mm}$ case. A $200 \times 100(z \times r)$ grid with a time step of $\Delta t=0.1 \mathrm{~s}$ was found to be sufficient to achieve grid size and time step independent solutions. A convergence criterion (maximum difference between two successive iterations and matrix residuals) of $10^{-5}$ was specified for all independent variables.

\section{Results and discussion}

Measured and predicted local temperatures for two representative melting experiments are reported in Fig. 3. For the HP case (Fig. 3a; no foil, $L_{t}=90 \mathrm{~mm}, L_{b}=55$ $\mathrm{mm}$ ), the agreement between measured and predicted local temperatures is good, with modest differences attributed to heat losses in the experiments. When the melt front passes through a thermocouple location, a sharp increase in temperature occurs. Hence, melting proceeds from top-to-bottom along the vertical plane of the thermocouples, as expected when melting is influenced by natural convection. In contrast, for the HP-Foil case (Fig. 3b), melting occurs nearly uniformly in the outward radial direction, also as expected since natural convection is suppressed by the horizontal foils and the HP is of relatively uniform temperature. It should be noted that upon melting (or expansion) of PCM between two adjacent foils, approximately similar forces apply on the top and 
bottom of each foil, minimizing foil displacement. Therefore, during the phase change the foil spacing remains small and noticeable natural convection flows are not established. The negligible foil displacement was also confirmed experimentally. Importantly, melting proceeds more rapidly for the case with foil, even though natural convection is suppressed. Note that for both cases of Fig. 3, the measured temperatures at the evaporation section of the HP are nearly constant at $T_{h t, \text { in }}=45^{\circ} \mathrm{C}$.

Predicted temperature distributions for the HP-Foil, HP and Rod cases with $L_{t}=90$ $\mathrm{mm}$ and $L_{b}=55 \mathrm{~mm}$ are shown in Fig. 4. The lower and outer boundaries of the PCM domain are identified with dashed lines, and the $T_{m}=28^{\circ} \mathrm{C}$ isotherm (the isotherm furthest from the centerline) corresponds to the PCM solid-liquid interface. The predictions correspond to, from left to right, melt fractions of $f_{\ell} \approx 0.2,0.4,0.6$, and 0.8 .

As evident, the HP-Foil configuration (Fig. 4a) experiences the most rapid melting, with attainment of $f_{\ell} \approx 0.8$ at $t \approx 1400 \mathrm{~s}$. In contrast, the $f_{\ell} \approx 0.8$ condition is attained at $t$ $\approx 5800 \mathrm{~s}$ and $t \approx 8200 \mathrm{~s}$ for the HP (Fig. 4b) and Rod (Fig. 4c) cases, respectively. Superior melting rates are achieved by the HP-foil configuration with only $f_{f} \approx 1.21 \%$ foil volume fraction, and are due to the increase in the effective thermal conductivity associated with usage of the foil, and to the reduced thermal mass of the HP relative to that of the solid rod.

Predicted and measured melting histories, reported in terms of the time variation of the liquid fraction, are shown in the LHS column of Fig. 5 for various $L_{t} / L_{b}$ ratios. Regardless of the value of $L_{t} / L_{b}$, the HP-foil configuration promotes the highest melting rates, and the Rod configuration exhibits the slowest melting, as expected. For the $L_{t}=90$ mm case (LHS Fig. 5a), the HP and Rod-Foil configurations yield nearly the same rates 
of melting. The relative insensitivity of the melting rate to $L_{t} / L_{b}$ reflects the fact that the thermal resistances associated with the bottom section of the heat pipe are small, relative to the thermal resistance posed by the PCM. Combining the HP with the foils results in an approximately $200 \%$ increase in the overall melting rate, compared to the HP configuration.

Melting performance may be quantified in terms of a melting effectiveness,

$$
\varepsilon_{m}=\frac{f_{\ell}(t)}{f_{\ell, r o d}(t)}
$$

where the Rod configuration is considered to be the basis for comparison. The temporal variation of $\varepsilon_{m}$ for various configurations is reported on the RHS of Fig. 5. The melting effectiveness is initially high for the HP-Foil case due to the combined effects of $(i)$ the low thermal mass of the HP relative to the rod, and (ii) the large radial effective thermal conductivity of the PCM-foil composite. The effectiveness of melting for the HP and Rod-Foil configurations moderately exceed that of the base configuration $\left(\varepsilon_{m}=1\right)$. An average melting effectiveness may be defined as the average of the $\varepsilon_{m}$ over the time of melting and dividing by the total melting time, yielding, for example, $\bar{\varepsilon}_{m}=4.7$ and 1.5 for the $L_{t}=90 \mathrm{~mm}$ case. As may be inferred from the LHS of Fig. 5, the average melting effectiveness values are insensitive to $L_{t} / L_{b}$ for the range of parameters considered here.

Solidification results are reported in Fig. 6. Here, a solidification effectiveness is defined as

$$
\varepsilon_{s}=\frac{1-f_{\ell}(t)}{1-f_{\ell, \text { rod }}(t)}
$$


and is used to compare the performance of the various configurations. Note that the difference between the HTF inlet temperature and the PCM melting temperature is the same for solidification (Fig. 6) as for melting (Fig. 5).

A comparison of the results of Figs. 5 and 6 shows that, in general, solidification occurs faster than melting, the difference in phase change rates being attributed to the higher thermal conductivity of the solid PCM, relative to that of the liquid PCM (Table 1). For the HP-Foil cases, the solidification rates are relatively constant throughout the phase change process, reflecting the relatively low thermal resistance between the HP and the solid-liquid interface. In contrast, solidification rates decay with time for the non-foil cases, as expected since the thermal resistance between the HTF and solid-liquid interface increases with time for configurations without foil. Predicted and measured phase change rates are in good agreement early on, but the agreement deteriorates in the later stages of solidification, particularly for the non-foil cases. The difference between the measured and predicted solidification rates is attributed to the probable development of thermal contact resistances at the HP-solid PCM (or rod-solid PCM) interface. In addition, the performance of the HP may be less robust during solidification than during melting since gravitational forces oppose the flow of the liquid HP working fluid during solidification; this effect is not included in the model.

Trends similar to those noted for melting (Fig. 5) are also evident for solidification (Fig. 6). Measured solidification rates associated with the HP-Foil configuration are approximately $900 \%$ and $600 \%$ higher than those of the Rod and HP configurations, respectively. Also, solidification rates for the HP configurations are increased by approximately $50 \%$ relative to the Rod configuration. The solidification 
effectiveness is slightly more sensitive to $L_{t} / L_{b}$ than the melting effectiveness, and the average solidification effectiveness is $\bar{\varepsilon}_{s}=4.29$ and 1.18 for the HP-Foil and HP configurations, respectively, for the $L_{t}=90 \mathrm{~mm}$ case.

The influence of the overall temperature difference, $\left|T_{h f}-T_{m}\right|$, on the melting and solidification for the HP-Foil case with $L_{t}=90 \mathrm{~mm}$ and $L_{b}=55 \mathrm{~mm}$ is shown in Fig. 7 . As expected, melting and solidification rates increase as the driving temperature increases. Again, the solidification rate is higher than the melting rate for each driving temperature because of the higher thermal conductivity of the solid phase.

\section{Conclusions}

An experimental and numerical investigation of melting and solidification involving a heat pipe acting in conjunction with metal foils has been conducted. The melting (solidification) rates associated with the HP-Foil configuration are approximately $300 \%$ (900\%) higher than that of a bare copper rod of the same physical dimensions as the HP. Superior phase change rates are achieved by utilizing only $1.21 \%$ foil volume fraction within the PCM in conjunction with the HP, permitting nearly the same total amount of latent energy to be stored within a fixed storage volume.

Integration of HPs with foils may be a preferred option to improve, perhaps significantly, the heat transfer rates in a broad range of applications involving melting and solidification and/or latent thermal energy storage. Not only is the thermal performance considered to be very good, the integrated HP-foil concept involves usage of less metal than solid metallic extended surfaces (such as the rod considered here) and, as such, can be less expensive and lighter-weight than conventional configurations. 


\section{Acknowledgement}

This work was supported by contracts from Boeing and the U.S. Department of Energy.

\section{References:}

[1] B. Zalba, J.M. Marin, L.F. Cabeza, H. Mehling, Review on thermal energy storage with phase change: materials, heat transfer analysis and applications, Applied Thermal Engineering 23 (3) (2003) 251-283.

[2] M.M. Farid, A.M. Khudhair, S.A.K. Razack, S. Al-Hallaj, A review on phase change energy storage: materials and applications, Energy Conversion Management 45 (9-10) (2004) 1597-1615.

[3] S.D. Sharma, K. Sagara, Latent heat storage materials and systems: a review, International Journal of Green Energy 2 (1) (2005) 1-56.

[4] F. Agyenim, N. Hewitt, P. Eames, M. Smyth, A review of materials, heat transfer and phase change problem formulation for latent heat thermal energy storage systems (LHTESS), Renewable and Sustainable Energy Reviews 14 (2) (2010) $615-628$.

[5] C.W. Lan, D.T. Yang, Dynamic simulation of the vertical zone-melting crystal growth, International Journal of Heat and Mass Transfer 41 (24) (1998) 43514373.

[6] Z. Liu, Z. Wang, C. Ma, An experimental study on heat transfer characteristics of heat pipe heat exchanger with latent heat storage, Part II: Simultaneous charging/ discharging modes, Energy Conversion and Management 47 (7-8) (2006) 967-991. 
[7] O. Mesalhy, K. Lafdi, A. Elgafy, K. Bowman, Numerical study for enhancing the thermal conductivity of phase change material (PCM) storage using high thermal conductivity porous matrix, Energy Conversion and Management 46 (6) (2005) 847-867.

[8] J.M. Martin, B. Zalba, L.F. Cabeza, H. Mehling, Improvement of a thermal energy storage using plates with paraffin-graphite composite, International Journal of Heat and Mass Transfer 48 (12) (2005) 2561-2570.

[9] S. Jegadheeswaran, S.D. Pohekar, Energy and exergy analysis of particle dispersed latent heat storage system, International Journal of Energy and Environment 1 (3) (2010) 445-458.

[10] H. Ettouney, I. Alatiqi, M. Al-Sahali, K. Al-Hajirie, Heat transfer enhancement in energy storage in spherical capsules filled with paraffin wax and beads, Energy Conversion and Management 47 (2) (2006) 211-228.

[11] A. Sari, C. Alkan, A. Karaipekli, O. Uzun, Microencapsulated n-octacosane as phase change material for thermal energy storage, Solar Energy 83 (10) (2009) 1757-1763.

[12] M.N.A. Hawlader, M.S. Uddin, M.M. Khin, Microencapsulated PCM thermal energy storage system, Applied Energy 74 (1-2) (2003) 195-202.

[13] M. Lacroix, M. Benmadda, Numerical simulation of natural convectiondominated melting and solidification from a finned vertical wall, Numerical Heat Transfer Part A-Application 31 (1) (1997) 71-86. 
[14] M. Lacroix, M. Benmadda, Analysis of natural convection melting from a heated wall with vertically oriented fins, International Journal of Numerical Methods for Heat and Fluid Flow 8 (4) (1998) 465-478.

[15] M.J. Huang, P.C. Eames, B. Norton, Thermal regulation of building-integrated photovoltaics using phase change materials, International Journal of Heat and Mass Transfer 47 (12-13) (2004) 2715-2733.

[16] V. Shatikian, G. Ziskind, R. Letan, Numerical investigation of a PCM-based heat sink with internal fins, International Journal of Heat and Mass Transfer 48 (17) (2005) 3689-3706.

[17] R. Akhilesh, A. Narasimhan, C. Balaji, Method to improve geometry for heat transfer enhancement in PCM composite heat sinks, International Journal of Heat and Mass Transfer 48 (13) (2005) 2759-2770.

[18] M. Gharebaghi, I. Sezai, Enhancement of heat transfer in latent heat storage modules with internal fins, Numerical Heat Transfer Part A - Application 53 (7) (2008) 749-765.

[19] N. Sharifi, T.L. Bergman, A. Faghri, Enhancement of PCM melting in enclosures with horizontally-finned internal surfaces, International Journal of Heat and Mass Transfer 54 (19-20) (2011) 4182-4192.

[20] A. Faghri, Heat Pipe Science and Technology, Taylor \& Francis, Washington, D. C., 1995 .

[21] A. Faghri, Thermal Energy Storage Heat Exchanger, US Patent No. 4976308, 1990. 
[22] A. Faghri, Micro Heat Pipe Energy Storage System, US Patent No. 5000252, 1991.

[23] B. Horbaniuc, G. Dumitrascu, A. Popescu, Mathematical models for the study of solidification within a longitudinally finned heat pipe latent heat thermal storage system, Energy Conversion and Management 40 (15-16) (1999) 1765-1774.

[24] Z. Liu, Z. Wang, C. Ma, An experimental study on heat transfer characteristics of heat pipe heat exchanger with latent heat storage. Part I: charging only and discharging only modes, Energy Conversion and Management 47 (7-8) (2006) 944-966.

[25] H. Shabgard, T.L. Bergman, N. Sharifi, A. Faghri, High temperature latent heat thermal energy storage using heat pipes, International Journal of Heat and Mass Transfer 53 (15-16) (2010) 2979-2988.

[26] C.W. Robak, T.L. Bergman, A. Faghri, Enhancement of latent heat energy storage using embedded heat pipes, International Journal of Heat and Mass Transfer 54 (15-16) (2011) 3476-3484.

[27] N. Sharifi, S. Wang, T.L. Bergman, A. Faghri, Heat pipe-assisted melting of a phase change material, International Journal of Heat and Mass Transfer 55 (1314) (2012) 3458-3469.

[28] C. Guo, W. Zhang, Numerical simulation and parametric study on new type of high temperature latent heat thermal energy storage system, Energy Conversion and Management 49 (5) (2008) 919-927.

[29] R. Bayón, E. Rojas, L. Valenzuela, E. Zarza, J. León, Analysis of the experimental behaviour of a $100 \mathrm{kWth}$ latent heat storage system for direct steam 
generation in solar thermal power plants, Applied Thermal Engineering 30 (1718) (2010) 2643-2651.

[30] M. Sugawara, Y. Komatsu, Y. Takahashi, Freezing enhancement around a horizontal tube using copper foil disks, Heat and Mass Transfer 47 (12) (2011) 1691-1698.

[31] R.S. Figliola, D.E. Beasley, Theory and Design for Mechanical Measurements, fourth ed., Wiley, Hoboken, 2006, pp. 148-190.

[32] A. Faghri, Y. Zhang, Transport Phenomena in Multiphase Systems, Academic Press, Elsevier, New York, 2006.

[33] A. Faghri, Y. Zhang, J. Howell, Advanced Heat and Mass Transfer, Global Digital Press, Columbia, Missouri, 2010.

[34] Y. Cao, A. Faghri, Transient two-dimensional compressible analysis for hightemperature heat pipes with pulsed heat input, Numerical Heat Transfer Part A Applications 18 (4) (1990a) 483-502.

[35] T.L. Bergman, A.S. Lavine, F.P. Incropera, D.P. Dewitt, Fundamentals of Heat and Mass Transfer, seventh ed., Wiley, Hoboken, 2011.

[36] The engineering toolbox, website: http://www.engineeringtoolbox.com/ 


\section{Appendix A. Measured Liquid Volume Fraction and Its Uncertainty}

Of interest is the time variation of the PCM liquid volume fraction, defined as $f_{\ell} \equiv V_{\ell, P C M} /\left(V_{\ell, P C M}+V_{s, P C M}\right)$, and its uncertainty. As suggested in Fig. A.1, during melting the initially solid PCM occupies the volume $V_{s, i}=\pi \mathrm{L}_{t}\left(r_{e, i}^{2}-r_{h p}^{2}\right)-V_{f}$, and the overlying air is of volume $V_{a i r, i}=\pi r_{e, i}^{2}\left(L_{e}-L_{t}\right)$ where $L_{e}$ is the internal height of the enclosure. The initial air pressure and temperature are $p_{a i r, i}$ and $T_{a i r, i}$, respectively. The decrease in air volume due to PCM expansion upon melting, coupled with the change in air temperature, causes a variation in the air pressure that is detected by the pressure transducer of Fig. 1. The measured air temperature and pressure are ultimately used to determine the instantaneous liquid fraction as follows.

As the PCM melts, the change in the volume occupied by solid PCM, $\Delta V_{s}$, can be determined from (i) knowledge of the change in air volume, $\Delta V_{a i r}=\left(V_{a i r}-V_{a i r, i}\right),(i i)$ the conservation of mass principle $\left(\Delta m_{s}+\Delta m_{\ell}=0\right)$ which may be written

$$
\rho_{s} \Delta V_{s}+\rho_{\ell} \Delta V_{\ell}=0
$$

and (iii) recognition that the total volume is fixed, or

$$
\Delta V_{\ell}+\Delta V_{s}+\Delta V_{\text {air }}=0
$$

Combining Eqs. A.1 and A.2 yields

$$
\Delta V_{s}=\frac{\Delta V_{\text {air }}}{\frac{\rho_{s}}{\rho_{\ell}}-1}
$$

Noting that $V_{s}=V_{s, i}+\Delta V_{s}$ and $V_{\ell}=\Delta V_{\ell}$, the definition of the liquid fraction and Eq. A.3 may be combined to yield 


$$
f_{\ell}=\frac{V_{\ell}}{V_{\ell}+V_{s}}=\frac{\Delta V_{\ell}}{\Delta V_{\ell}+V_{s}}=\frac{\Delta V_{s}+\Delta V_{\text {air }}}{\Delta V_{\text {air }}-V_{s, i}}
$$

Assuming the air is well-mixed and behaves as an ideal gas,

$$
V_{\text {air }}=\frac{m_{a i r} R T_{\text {air }}}{p_{\text {air }}} \quad \text { and } \quad m_{\text {air }}=\frac{V_{\text {air }, i} p_{\text {air }, i}}{R T_{\text {air }, i}}
$$

and, using the expression $p_{a i r}=p_{a i r, i}+\Delta p_{a i r}$, Eqs. (A.4) and (A.5) may be combined with the definitions of the initial air and PCM volumes to yield

$$
f_{\ell}=\frac{\frac{1}{1-\frac{V_{s, r e f}}{V_{\ell, r e f}}} \times \pi r_{e, i}^{2}\left(L_{e}-L_{t}\right) \times\left(\frac{p_{\text {air }, i}}{T_{\text {air }, i}} \frac{T_{\text {air }}}{\left(p_{\text {air }, i}+\Delta p_{\text {air }}\right)}-1\right)}{\pi r_{e, i}^{2}\left(L_{e}-L_{t}\right) \times\left(\frac{p_{\text {air }, i}}{T_{\text {air }, i}} \frac{T_{\text {air }}}{\left(p_{\text {air }, i}+\Delta p_{\text {air }}\right)}-1\right)-\pi\left(r_{e, i}^{2}-r_{h p}^{2}\right) L_{t}+\frac{m_{f}}{\rho_{f}}}
$$

All of the parameters of Eq. A.6 are known ( $p_{\text {air }, i}$ is taken to be standard atmospheric pressure in Storrs, CT) except for $\Delta p_{\text {air }}$, and $T_{\text {air }}$ which are determined experimentally. However, the liquid fraction calculated using Eq. A.6 is highly sensitive to the ratio of the PCM phase densities, and substantial differences in the density ratio exist, based upon density values of the individual phases reported in the literature. As such, the density ratio was determined experimentally by solidifying a mass of de-gassed PCM in a graduated cylinder to determine the volume of the PCM in both solid phase $\left(V_{s, r e f}\right)$ and liquid phase $\left(V_{\ell, r e f}\right)$ as reported in Table A.1.

The uncertainty of the PCM liquid volume fraction is determined using the sequential perturbation method [31]. The uncertainty of each independent variable appearing in Eq. A.6 is calculated based on the resolution ( res ) and accuracy ( acc ) 
associated with its measurement as $u=\sqrt{r e s^{2}+a c c^{2}}$. Note that the air is assumed to be well-mixed and $T_{a i r}$ is taken as the average of $T_{5}$ and $T_{10}$. Since $\Delta p_{\text {air }}$, and $T_{\text {air }}$ vary with time, the uncertainty in $f_{\ell}$ also changes with time and is calculated at each instant. A similar analysis is used for the solidification process. 


\section{Table Captions}

Table A.1. Measured parameters and the corresponding uncertainties. All parameters and uncertainties for the experiment involving the rod are the same as those involving the HP. The diameters of the HP and rod are equal.

Table 1 . Thermophysical properties at $T=301 \mathrm{~K}$.

Table 2. Thermocouple locations, See Fig. 1.

Table 3. Effective thermophysical properties. 
Table A.1. Measured parameters and the corresponding uncertainties. All parameters and uncertainties for the experiment involving the rod are the same as those involving the HP. The diameters of the HP and rod are equal.

\begin{tabular}{|l|c|c|c|c|}
\hline $\begin{array}{c}\text { Independent } \\
\text { variable }\end{array}$ & Value & $\begin{array}{c}\text { Resolution } \\
(\text { res })\end{array}$ & $\begin{array}{c}\text { Accuracy } \\
(\text { acc })\end{array}$ & $\begin{array}{c}\text { Uncertainty } \\
(u)\end{array}$ \\
\hline$r_{e, i}[1]$ & $20.64 \mathrm{~mm}$ & $0.025 \mathrm{~mm}$ & $\pm 0.051 \mathrm{~mm}$ & $\pm 0.057 \mathrm{~mm}$ \\
\hline$r_{h p}$ or $r_{\text {rod }}[1]$ & $3.01 \mathrm{~mm}$ & $0.025 \mathrm{~mm}$ & $\pm 0.051 \mathrm{~mm}$ & $\pm 0.057 \mathrm{~mm}$ \\
\hline$p_{\text {air }, i}[2]$ & $99.1 \mathrm{kPa}$ & - & $\pm 1 \mathrm{kPa}$ & $\pm 1 \mathrm{kPa}$ \\
\hline$T_{\text {air, } i}[3]$ & $298 \mathrm{~K}$ & - & $\pm 0.1 \mathrm{~K}$ & $\pm 0.1 \mathrm{~K}$ \\
\hline$T_{\text {air }}[3]$ & $T_{\text {air }}(t)$ & - & $\pm 0.1 \mathrm{~K}$ & $\pm 0.1 \mathrm{~K}$ \\
\hline$\Delta p_{\text {air }}[4]$ & $\Delta p_{\text {air }}(t)$ & $0.1 \mathrm{kPa}$ & $\pm 0.02 \Delta p_{\text {air }}(t)$ & $\begin{array}{c}\text { varies with } \\
\text { time }\end{array}$ \\
\hline$m_{f}[5]$ & $3.8 \mathrm{~g}$ & $0.1 \mathrm{~g}$ & $\pm 0.1 \mathrm{~g}$ & $\pm 0.141 \mathrm{~g}$ \\
\hline$L_{t}$ & $90 \mathrm{~mm}$ & $1 \mathrm{~mm}$ & $\pm 1 \mathrm{~mm}$ & $\pm 1.41 \mathrm{~mm}$ \\
\hline$L_{e}$ & $125 \mathrm{~mm}$ & $1 \mathrm{~mm}$ & $\pm 1 \mathrm{~mm}$ & $\pm 1.41 \mathrm{~mm}$ \\
\hline$V_{s, r e f}$ & $22.7 \mathrm{ml}$ & $0.1 \mathrm{ml}$ & $\pm 0.15 \mathrm{ml}$ & $\pm 0.18 \mathrm{ml}$ \\
\hline$V_{\ell, r e f}$ & $24.7 \mathrm{ml}$ & $0.1 \mathrm{ml}$ & $\pm 0.15 \mathrm{ml}$ & $\pm 0.18 \mathrm{ml}$ \\
\hline
\end{tabular}

[1] $r_{e, i}, r_{h p}, r_{\text {rod }}:$ http://ecatalog.mitutoyo.com/Dial-Calipers-Series-505-C1387.aspx

[2] $p_{\text {air }, i}:$ http://www.idcide.com/citydata/ct/storrs.htm (elevation of Storrs, CT)

[3] $T_{\text {air,i }}, T_{\text {air }}:$ http://www.ni.com/pdf/manuals/372499b.pdf (temperature accuracy/uncertainty)

[4] $\Delta p_{\text {air }}:$ http://www.sperdirect.com/mas_assets/manuals/840065-i.pdf (meter resolution \& accuracy)

[5] $m_{f}:$ Mettler Toledo XS10001M Scale (mass resolution \& accuracy) 
Table 1 . Thermophysical properties at $T=301 \mathrm{~K}$.

\begin{tabular}{|c|c|c|c|c|c|}
\hline & PCM & HP working fluid & HP or Rod & Foil & Enclosure \\
\hline Material & $\begin{array}{c}\text { n-Octadecane } \\
{[26]}\end{array}$ & $\begin{array}{l}\text { Water } \\
{[20]}\end{array}$ & $\begin{array}{c}\text { Copper } \\
{[35]}\end{array}$ & $\begin{array}{l}\text { Aluminum } \\
\text { [35] }\end{array}$ & $\begin{array}{c}\text { Acrylic } \\
{[36]}\end{array}$ \\
\hline Density, $\rho\left(\mathrm{kg} / \mathrm{m}^{3}\right)$ & $\begin{array}{l}770 \text { (liquid) } \\
800 \text { (solid) }\end{array}$ & 996.6 (liquid) & 8933 & 2702 & 1150 \\
\hline Thermal conductivity, $k(\mathrm{~W} / \mathrm{m} \cdot \mathrm{K})$ & $\begin{array}{c}0.148 \text { (liquid) } \\
0.358 \text { (solid) }\end{array}$ & $\begin{array}{c}0.6132 \text { (liquid) } \\
0.01932 \text { (vapor) }\end{array}$ & 401 & 237 & 0.2 \\
\hline Specific heat, $c_{p}(\mathrm{~J} / \mathrm{kg} \cdot \mathrm{K})$ & $\begin{array}{c}2160 \text { (liquid) } \\
1912 \text { (solid) }\end{array}$ & $\begin{array}{l}4181 \text { (liquid) } \\
1882 \text { (vapor) }\end{array}$ & 385 & 903 & 1470 \\
\hline Viscosity, $\mu(\mathrm{Pa} \cdot \mathrm{s})$ & $3.09 \times 10^{-3}$ & $\begin{array}{l}8614 \times 10^{-7} \\
\text { (liquid) } \\
91.74 \times 10^{-7} \\
\text { (vapor) }\end{array}$ & & & \\
\hline Latent heat, $h_{s l}$ or $h_{f g}(\mathrm{~kJ} / \mathrm{kg})$ & 243.5 & 2434.9 & & & \\
\hline Melting point, $T_{m}(\mathrm{~K})$ & 301 & & & & \\
\hline Vapor pressure, $p_{\text {sat }}(\mathrm{Pa})$ & & 4352 & & & \\
\hline Thermal expansion coefficient, $\beta\left(\mathrm{K}^{-1}\right)$ & $9 \times 10^{-4}$ & & & & \\
\hline
\end{tabular}


Table 2. Thermocouple locations, See Fig. 1.

\begin{tabular}{|r|c|l|}
\hline Thermocouple & $r$-coordinate $(\mathrm{mm})$ & $z$-coordinate $(\mathrm{mm})$ \\
\hline$T_{1}$ & 13 & 105 \\
\hline$T_{2}$ & 13 & 125 \\
\hline$T_{3}$ & 13 & 145 \\
\hline$T_{4}$ & 13 & 165 \\
\hline$T_{5}$ & 13 & 195 \\
\hline$T_{6}$ & -13 & 105 \\
\hline$T_{7}$ & -13 & 125 \\
\hline$T_{8}$ & -13 & 145 \\
\hline$T_{9}$ & -13 & 165 \\
\hline$T_{10}$ & -13 & 195 \\
\hline$T_{11}$ & 3 & 15 \\
\hline$T_{12}$ & 3 & 30 \\
\hline$T_{13}$ & 3 & 45 \\
\hline
\end{tabular}


Table 3. Effective thermophysical properties.

\begin{tabular}{|l|c|c|}
\hline & Region I, $\left(f_{f}=0.0121\right)$ & Region II $\left(f_{f}=0.0116\right)$ \\
\hline$\rho_{\text {eff }}\left(\mathrm{kg} / \mathrm{m}^{3}\right)$ & $793($ liquid) & $792($ liquid $)$ \\
& 823 (solid) & 822 (solid) \\
\hline$c_{p, \text { eff }}(\mathrm{J} / \mathrm{kg} \cdot \mathrm{K})$ & 2109 (liquid) & 2110 (liquid) \\
& 1872 (solid) & 1873 (solid) \\
\hline$h_{s l, e f f}(\mathrm{~kJ} / \mathrm{kg})$ & $233.5($ liquid) & 233.9 (liquid) \\
& 233.8 (solid) & 234.2 (solid) \\
\hline$k_{\text {eff,r }}(\mathrm{W} / \mathrm{m} \cdot \mathrm{K})$ & $3.01($ liquid) & $0.188($ liquid) \\
& $3.21($ solid) & 0.454 (solid) \\
\hline$k_{\text {eff, }, z}(\mathrm{~W} / \mathrm{m} \cdot \mathrm{K})$ & 0.149 (liquid) & 0.149 (liquid) \\
& 0.362 (solid) & 0.362 (solid) \\
\hline
\end{tabular}




\section{Figure Captions}

Fig. 1. Experimental setup.

Fig. 2. Test cell geometry: (a) computational domain, (b) PCM sub-regions.

Fig. 3. Temperatures within the PCM (left) and on the HP evaporator section (right) during melting with $L_{t}=90 \mathrm{~mm}, L_{b}=55 \mathrm{~mm}$ : (a) HP, (b) HP-Foil $\left(f_{f}=0.0121\right)$.

Fig. 4. Predicted temperature distributions for the conditions of Fig. 3. Results are for (a) HP-Foil $\left(f_{\ell}=0.0121\right)$, (b) HP, and (c) Rod. Isotherms are shown at intervals of $1 \mathrm{~K}$ over the range $28^{\circ} \mathrm{C} \leq T \leq 45^{\circ} \mathrm{C}$ for all cases.

Fig. 5. Melting liquid fraction (left) and effectiveness (right) histories for $T_{h f f}-T_{m}=17^{\circ} \mathrm{C}$ and $f_{f}=$ 0.0121: (a) $L_{t}=90 \mathrm{~mm}, L_{b}=55 \mathrm{~mm}$, (b) $L_{t}=80 \mathrm{~mm}, L_{b}=65 \mathrm{~mm}$, (c) $L_{t}=72 \mathrm{~mm}, L_{b}=73 \mathrm{~mm}$.

Fig. 6. Solidification liquid fraction (left) and effectiveness (right) histories for $T_{m}-T_{h t f}=17^{\circ} \mathrm{C}$ and $f_{f}=0.0121:$ (a) $L_{t}=90 \mathrm{~mm}, L_{b}=55 \mathrm{~mm}$, (b) $L_{t}=80 \mathrm{~mm}, L_{b}=65 \mathrm{~mm}$, (c) $L_{t}=72 \mathrm{~mm}, L_{b}=73$ $\mathrm{mm}$.

Fig. 7. Liquid fraction histories for the HP-Foil configuration $\left(L_{t}=90 \mathrm{~mm}, L_{b}=55 \mathrm{~mm}, f_{f}=\right.$ 0.0121 ), (a) melting for various $T_{h t f}-T_{m}$, (b) solidification for various $T_{m}-T_{h t f}$.

Fig. A.1. Conceptual melting process: (a) initial (100\% solid), (b) solid and liquid PCM, (c) final (100\% liquid). 


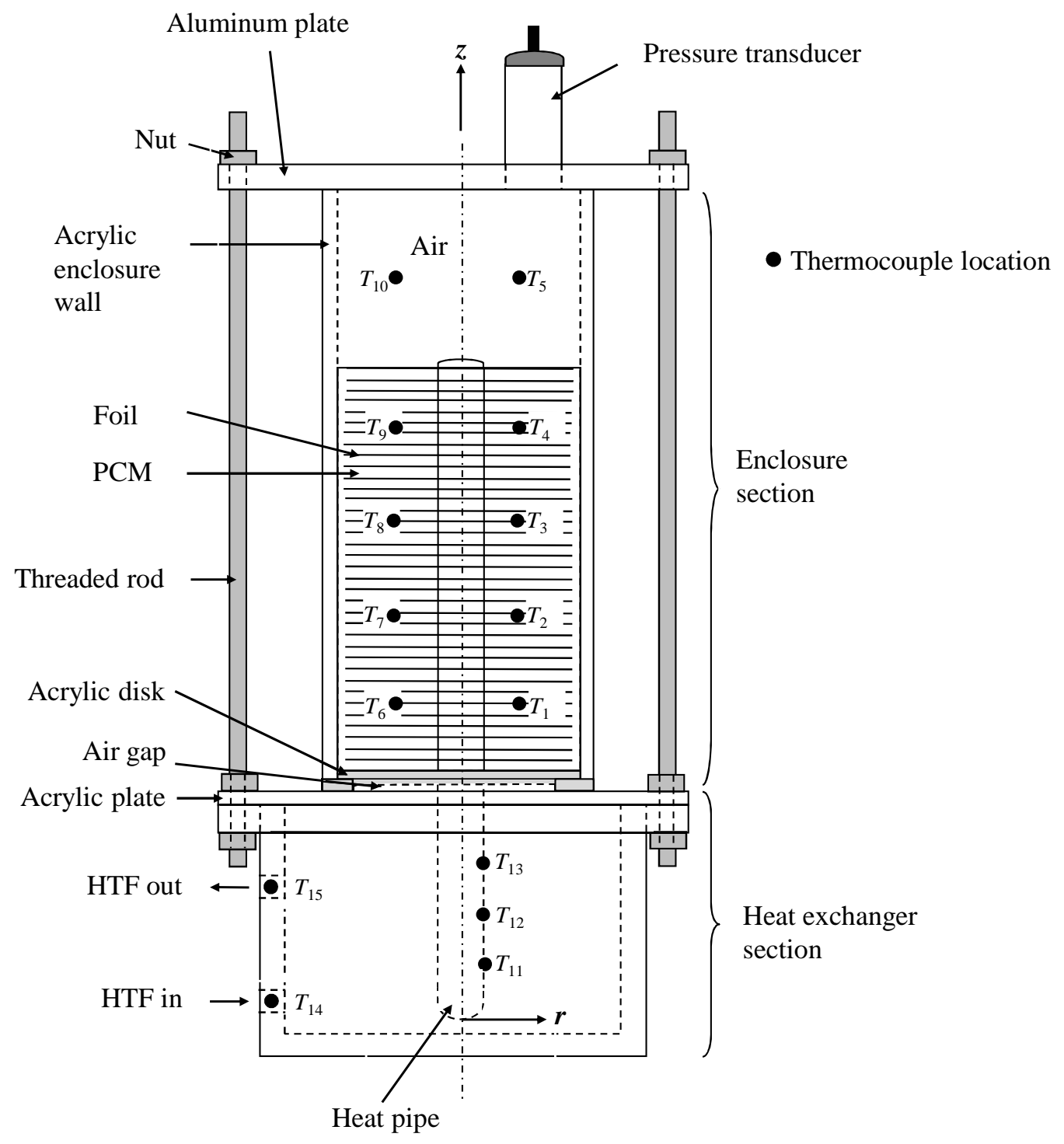

Fig. 1. Experimental setup. 


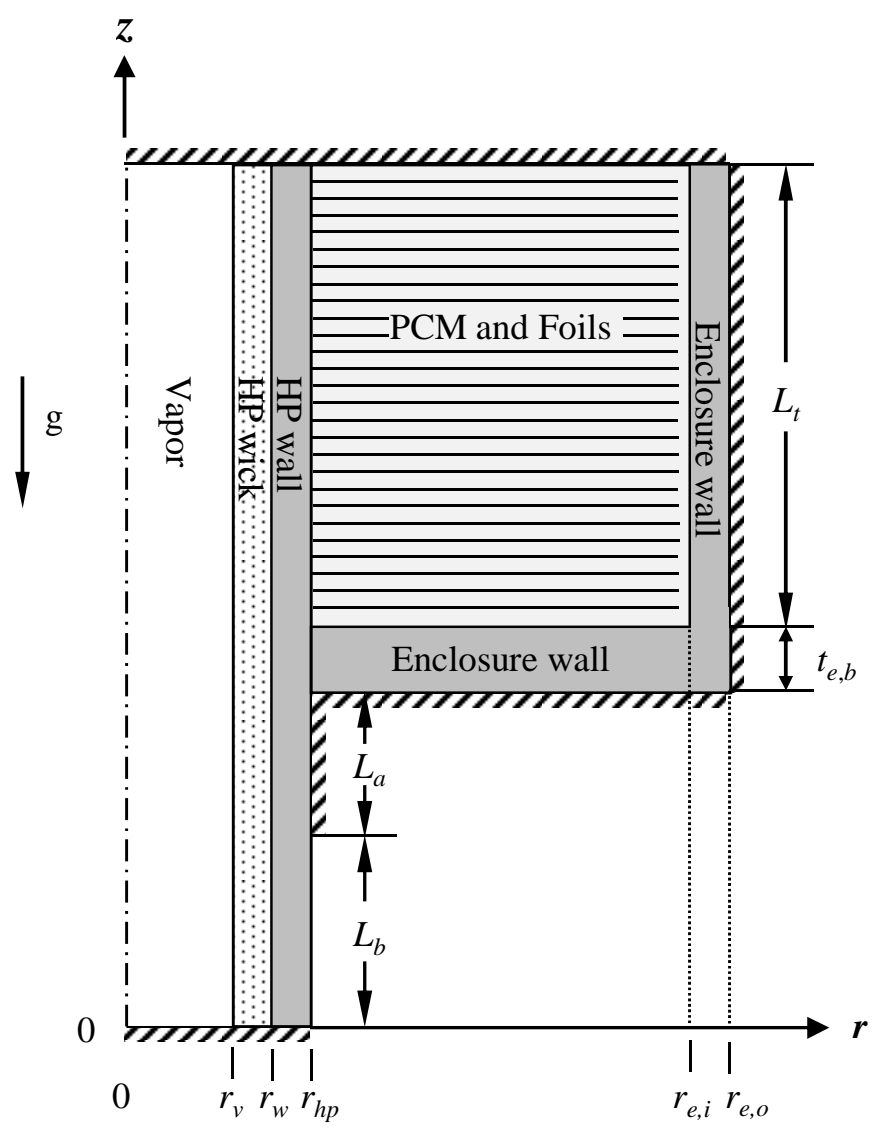

(a)

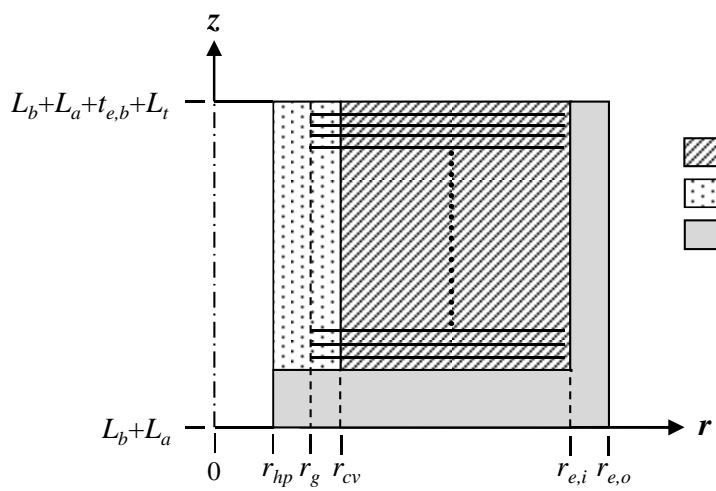

(b)

Fig. 2. Test cell geometry: (a) computational domain, (b) PCM sub-regions. 

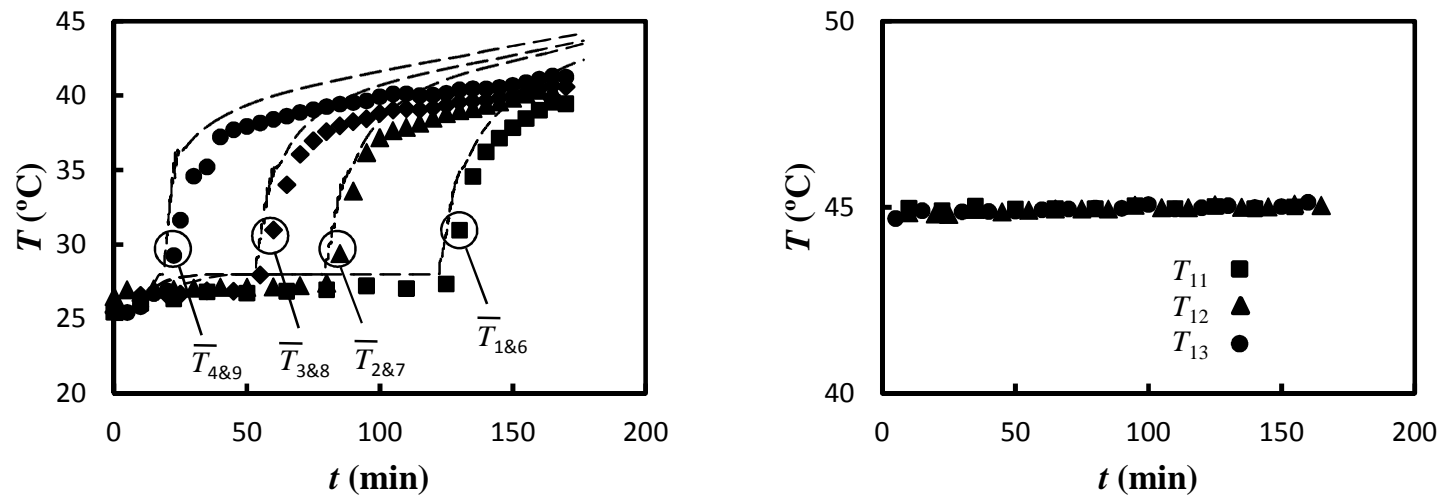

(a)
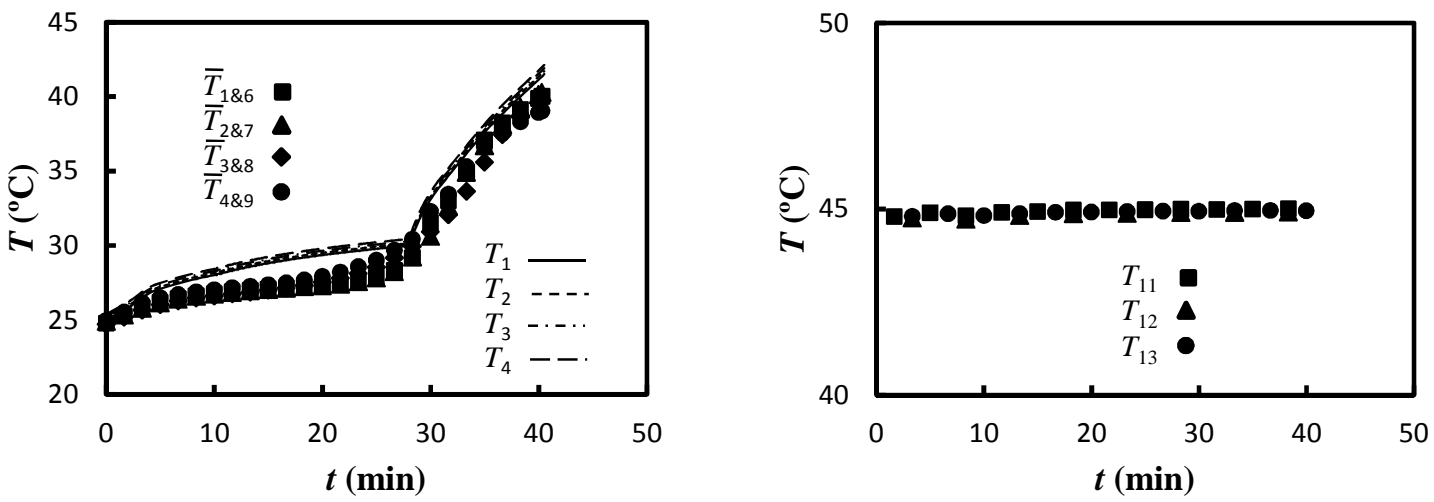

(b)

Fig. 3. Temperatures within the PCM (left) and on the HP evaporator section (right) during melting with $L_{t}=90 \mathrm{~mm}, L_{b}=55 \mathrm{~mm}$ : (a) HP, (b) HP-Foil $\left(f_{f}=0.0121\right)$. 

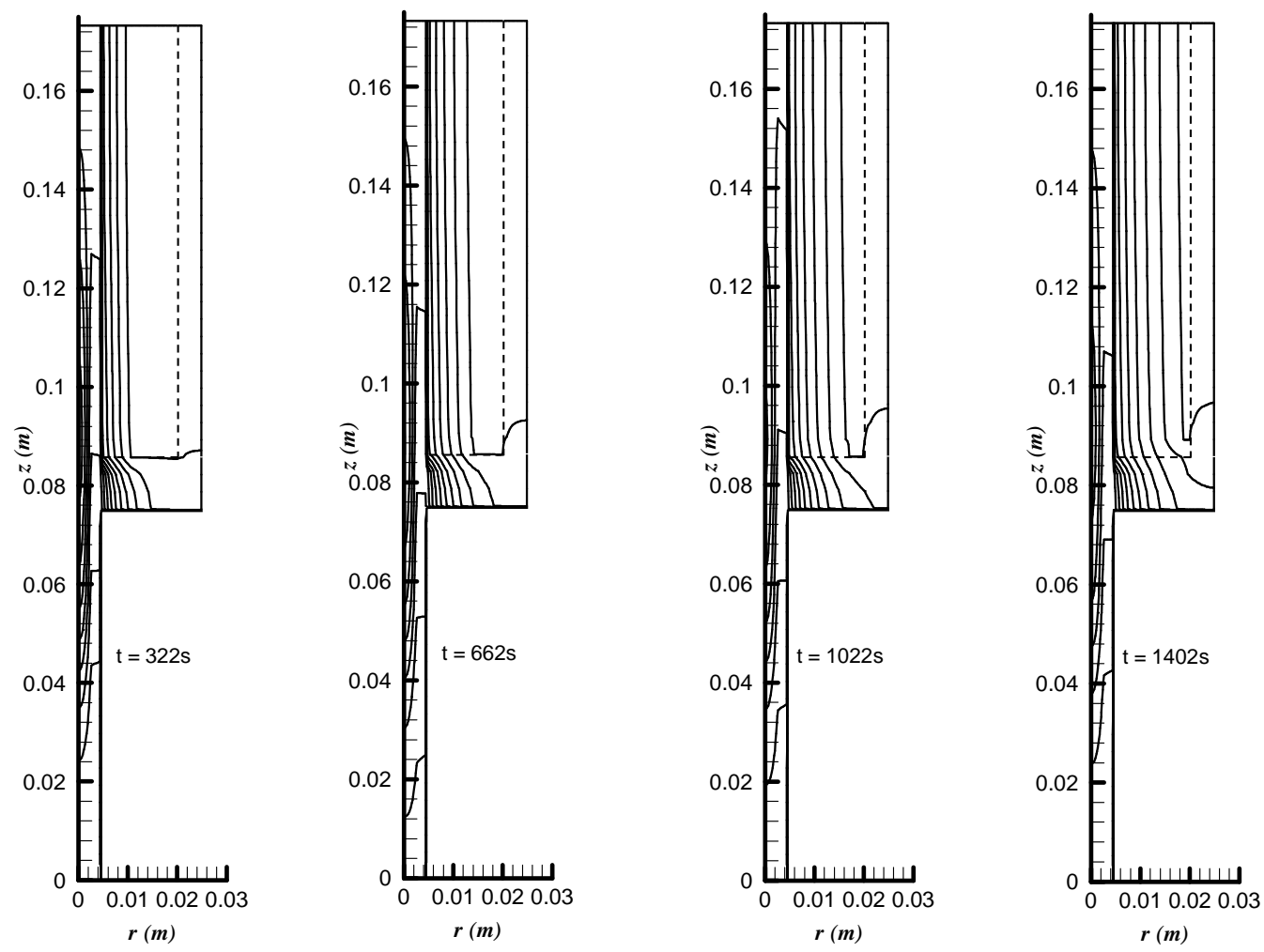

(a)
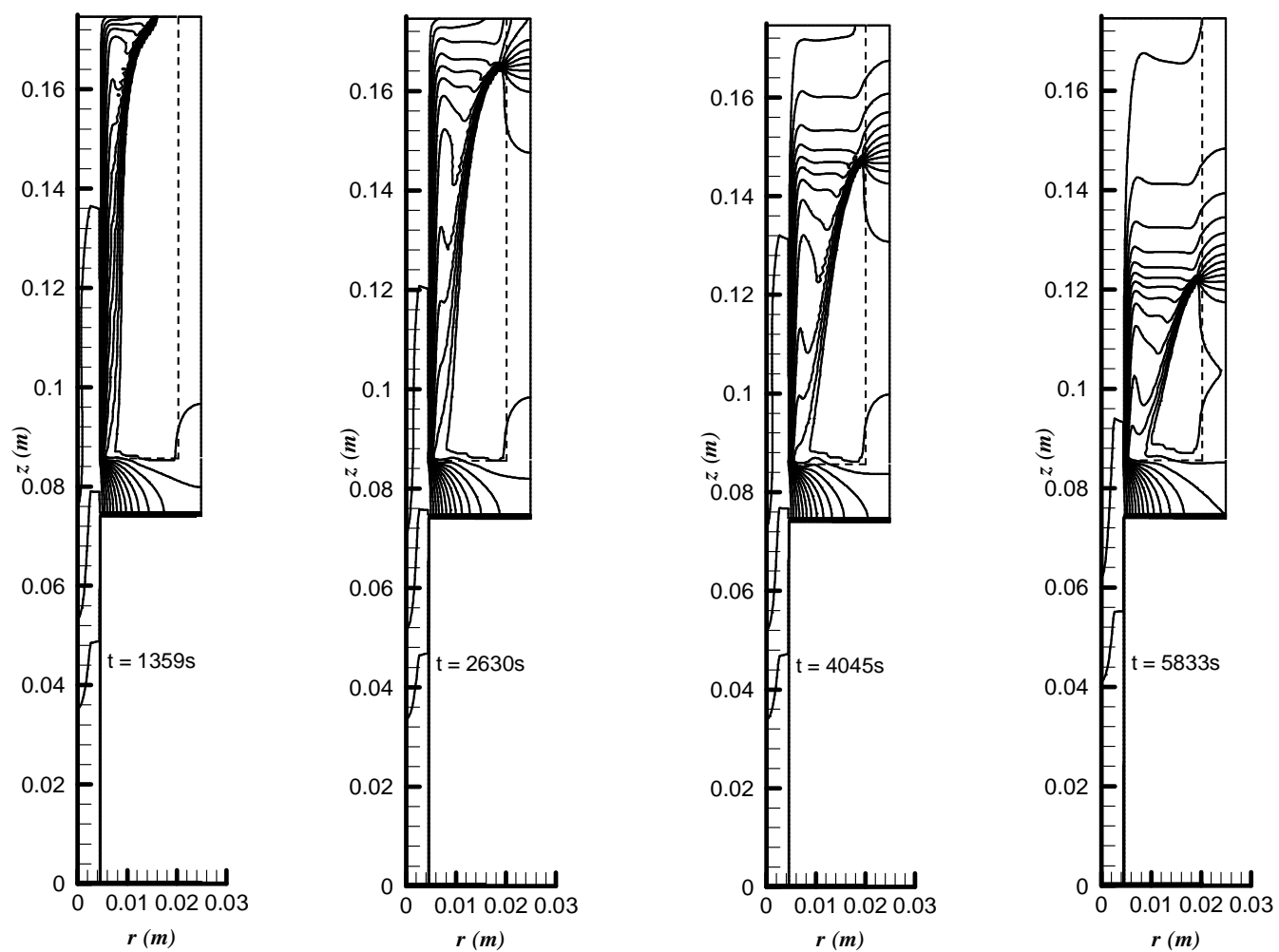

(b) 

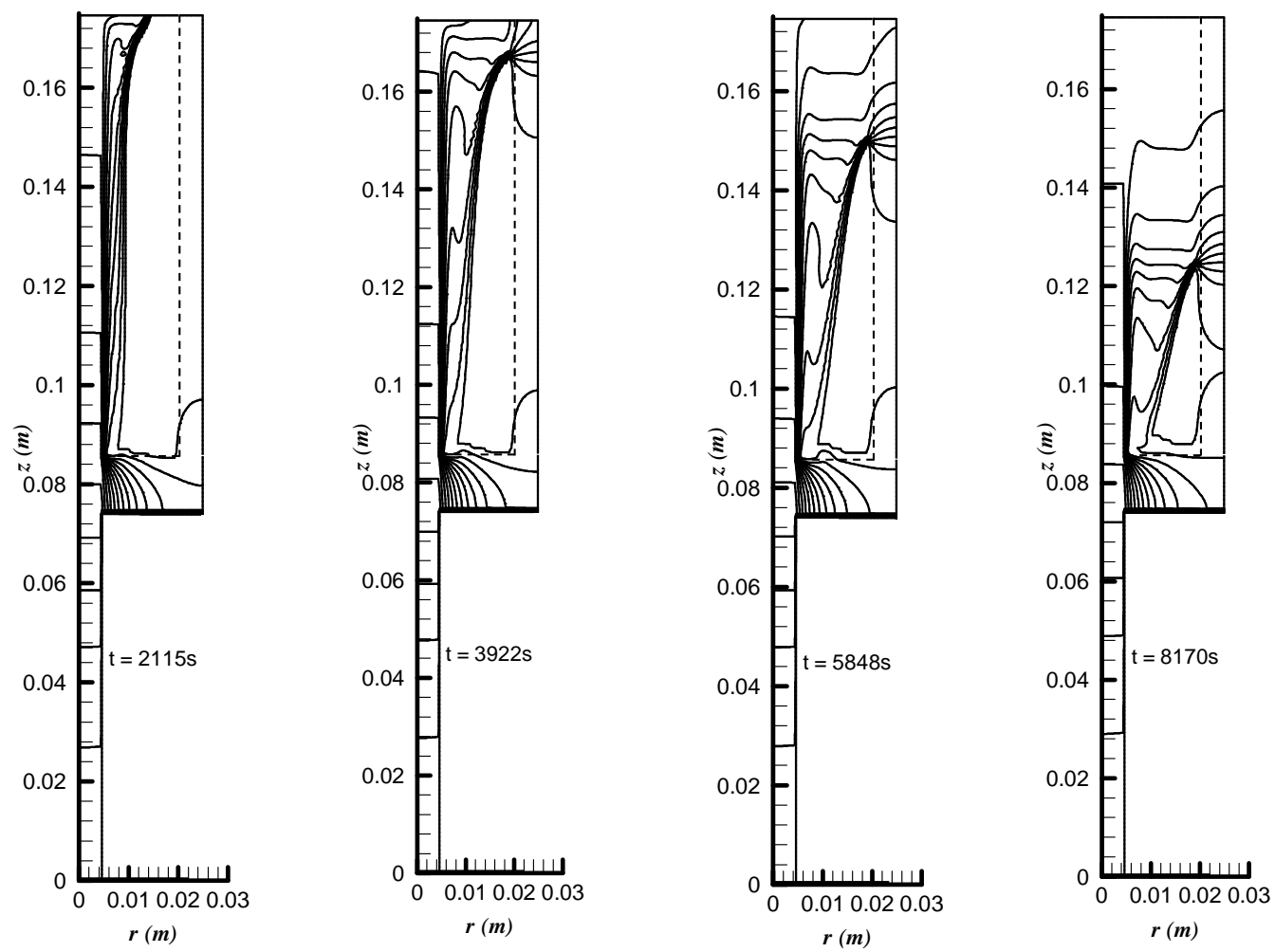

(c)

Fig. 4. Predicted temperature distributions for the conditions of Fig. 3. Results are for (a) HP-Foil $\left(f_{\ell}=0.0121\right)$, (b) HP, and (c) Rod. Isotherms are shown at intervals of $1 \mathrm{~K}$ over the range $28^{\circ} \mathrm{C} \leq T \leq 45^{\circ} \mathrm{C}$ for all cases. 

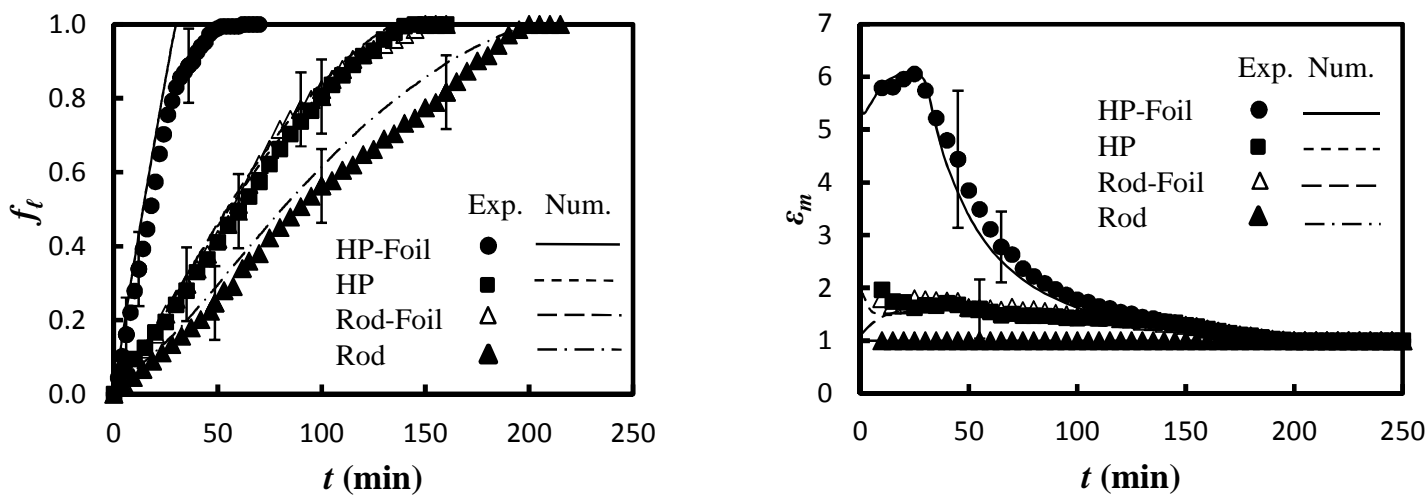

(a)
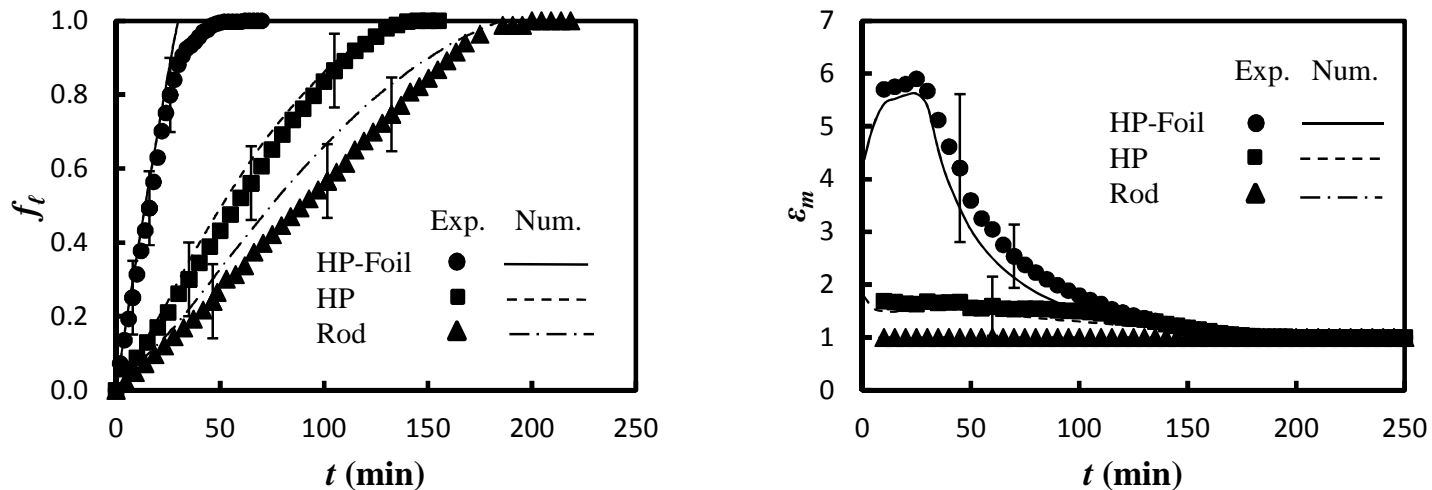

(b)
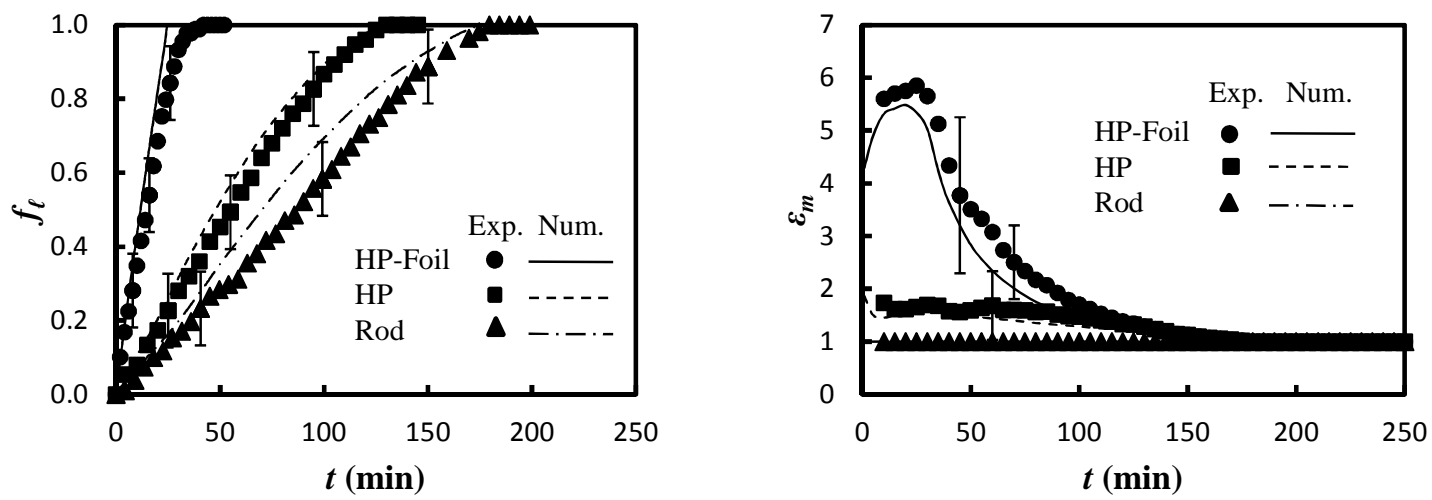

(c)

Fig. 5. Melting liquid fraction (left) and effectiveness (right) histories for $T_{h t f}-T_{m}=17^{\circ} \mathrm{C}$ and $f_{f}=$ 0.0121: (a) $L_{t}=90 \mathrm{~mm}, L_{b}=55 \mathrm{~mm}$, (b) $L_{t}=80 \mathrm{~mm}, L_{b}=65 \mathrm{~mm}$, (c) $L_{t}=72 \mathrm{~mm}, L_{b}=73 \mathrm{~mm}$. 

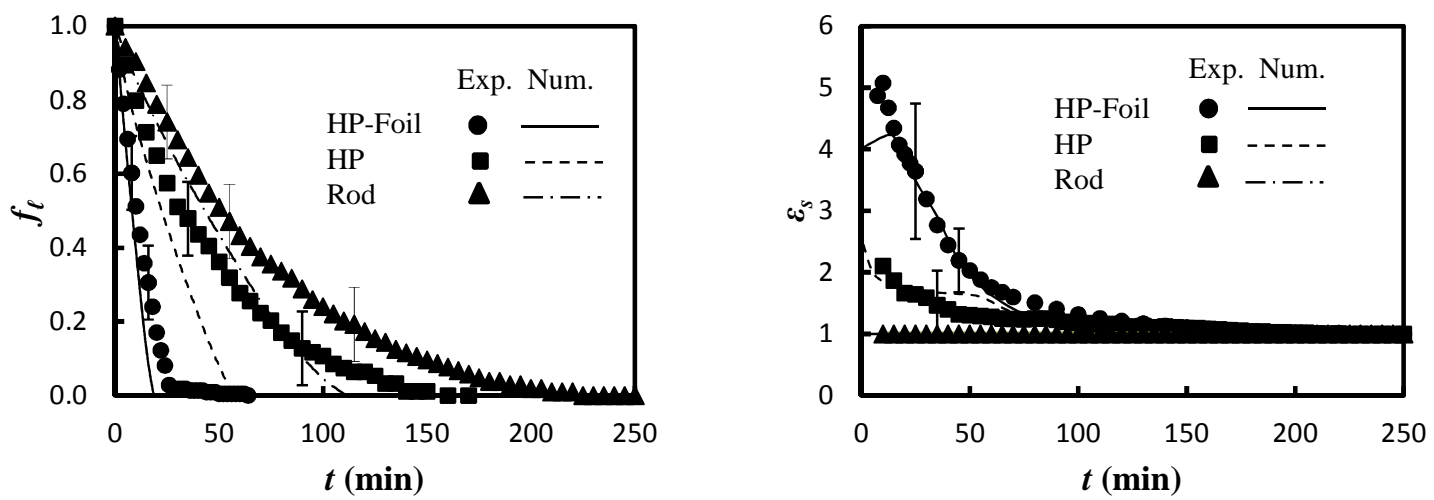

(a)
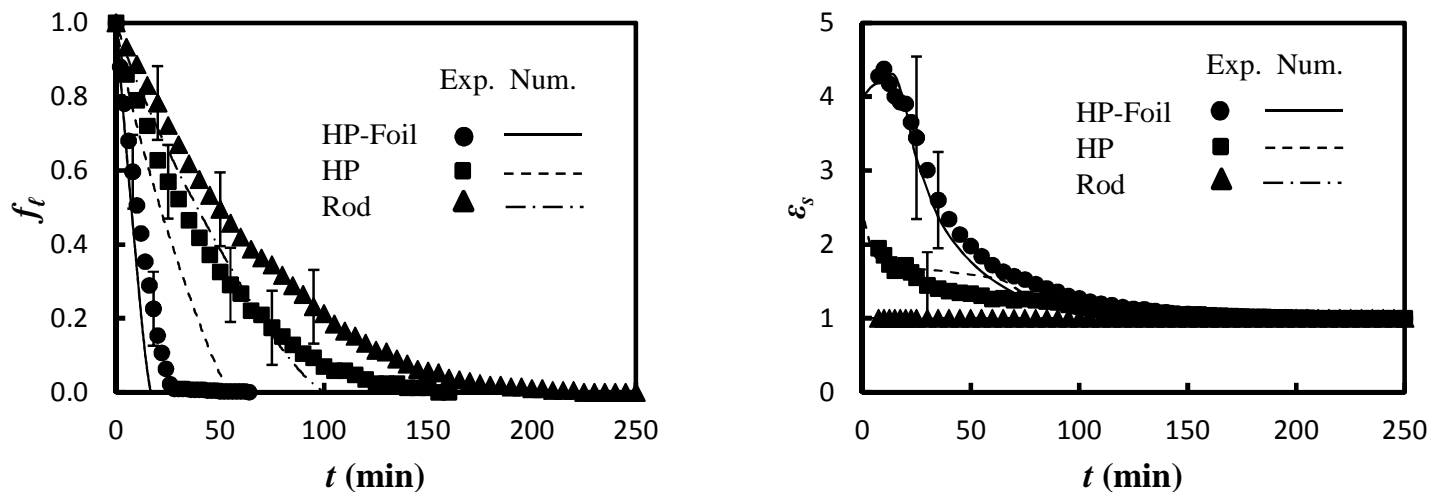

(b)
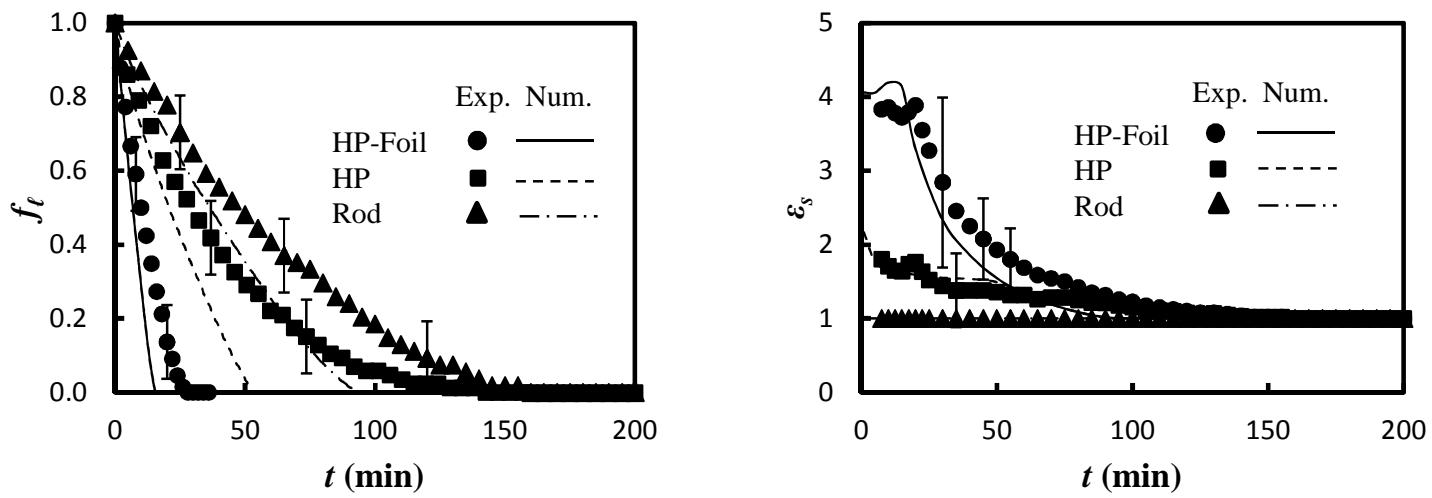

(c)

Fig. 6. Solidification liquid fraction (left) and effectiveness (right) histories for $T_{m}-T_{h t f}=17^{\circ} \mathrm{C}$ and $f_{f}=0.0121:$ (a) $L_{t}=90 \mathrm{~mm}, L_{b}=55 \mathrm{~mm}$, (b) $L_{t}=80 \mathrm{~mm}, L_{b}=65 \mathrm{~mm}$, (c) $L_{t}=72 \mathrm{~mm}, L_{b}=73$ $\mathrm{mm}$. 


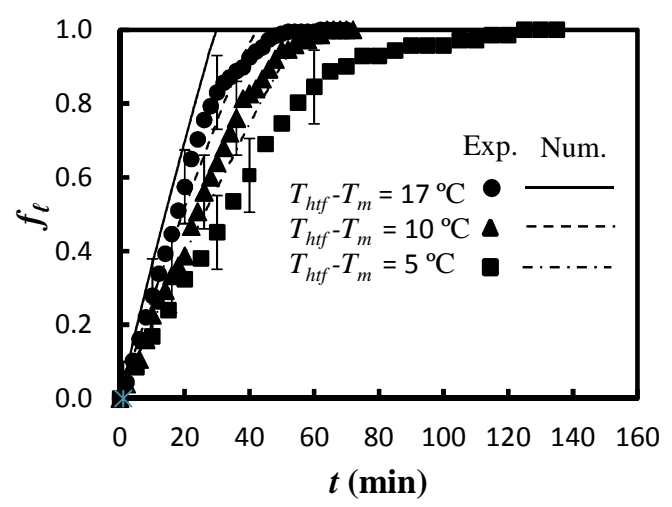

(a)

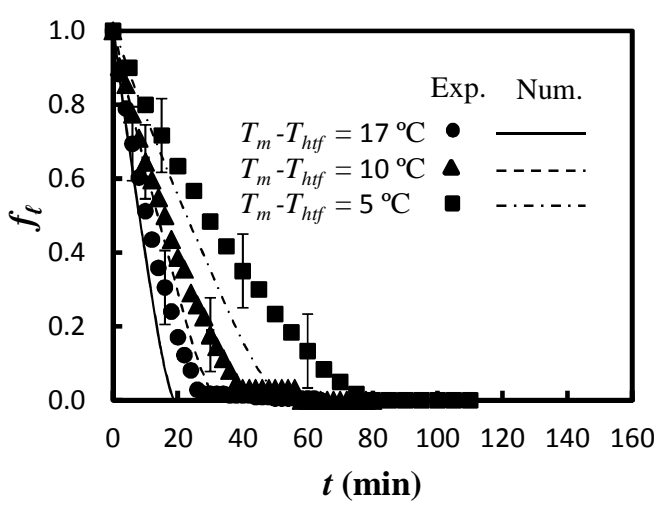

(b)

Fig. 7. Liquid fraction histories for the HP-Foil configuration $\left(L_{t}=90 \mathrm{~mm}, L_{b}=55 \mathrm{~mm}, f_{f}=\right.$ 0.0121 ), (a) melting for various $T_{h t f}-T_{m}$, (b) solidification for various $T_{m}-T_{h t f}$.

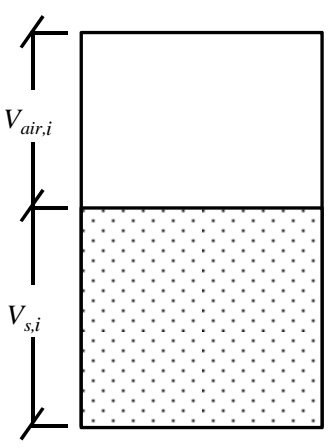

(a)

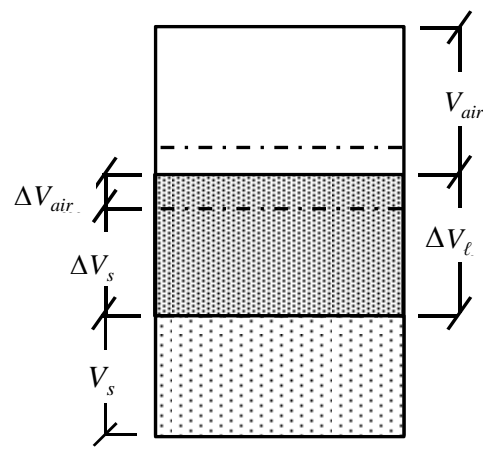

(b)

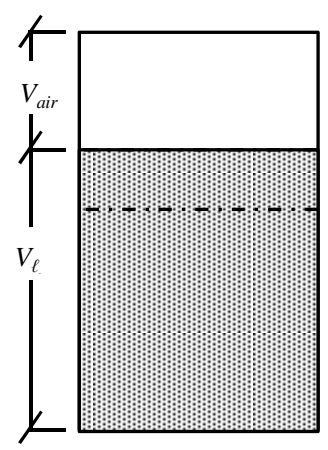

(c)

Fig. A.1. Conceptual melting process: (a) initial (100\% solid), (b) solid and liquid PCM, (c) final (100\% liquid). 


\section{Table Captions}

Table A.1 Measured parameters and the corresponding uncertainties. All parameters and uncertainties for the experiment involving the rod are the same as those involving the HP. The diameters of the HP and rod are equal.

Table 1 . Thermophysical properties at $T=301 \mathrm{~K}$.

Table 2. Thermocouple locations, See Fig. 1.

Table 3. Effective thermophysical properties. 
Table A.1 Measured parameters and the corresponding uncertainties. All parameters and uncertainties for the experiment involving the rod are the same as those involving the HP. The diameters of the HP and rod are equal.

\begin{tabular}{|l|c|c|c|c|}
\hline $\begin{array}{c}\text { Independent } \\
\text { variable }\end{array}$ & Value & $\begin{array}{c}\text { Resolution } \\
(\text { res })\end{array}$ & $\begin{array}{c}\text { Accuracy } \\
(\text { acc })\end{array}$ & $\begin{array}{c}\text { Uncertainty } \\
(u)\end{array}$ \\
\hline$r_{e, i}[1]$ & $20.64 \mathrm{~mm}$ & $0.025 \mathrm{~mm}$ & $\pm 0.051 \mathrm{~mm}$ & $\pm 0.057 \mathrm{~mm}$ \\
\hline$r_{h p}$ or $r_{\text {rod }}[1]$ & $3.01 \mathrm{~mm}$ & $0.025 \mathrm{~mm}$ & $\pm 0.051 \mathrm{~mm}$ & $\pm 0.057 \mathrm{~mm}$ \\
\hline$p_{\text {air }, i}[2]$ & $99.1 \mathrm{kPa}$ & - & $\pm 1 \mathrm{kPa}$ & $\pm 1 \mathrm{kPa}$ \\
\hline$T_{\text {air }, i}[3]$ & $298 \mathrm{~K}$ & - & $\pm 0.1 \mathrm{~K}$ & $\pm 0.1 \mathrm{~K}$ \\
\hline$T_{\text {air }}[3]$ & $T_{\text {air }}(t)$ & - & $\pm 0.1 \mathrm{~K}$ & $\pm 0.1 \mathrm{~K}$ \\
\hline$\Delta p_{\text {air }}[4]$ & $\Delta p_{\text {air }}(t)$ & $0.1 \mathrm{kPa}$ & $\pm 0.02 \Delta p_{\text {air }}(t)$ & $\begin{array}{c}\text { varies with } \\
\text { time }\end{array}$ \\
\hline$m_{f}[5]$ & $3.8 \mathrm{~g}$ & $0.1 \mathrm{~g}$ & $\pm 0.1 \mathrm{~g}$ & $\pm 0.141 \mathrm{~g}$ \\
\hline$L_{t}$ & $90 \mathrm{~mm}$ & $1 \mathrm{~mm}$ & $\pm 1 \mathrm{~mm}$ & $\pm 1.41 \mathrm{~mm}$ \\
\hline$L_{e}$ & $125 \mathrm{~mm}$ & $1 \mathrm{~mm}$ & $\pm 1 \mathrm{~mm}$ & $\pm 1.41 \mathrm{~mm}$ \\
\hline$V_{s, r e f}$ & $22.7 \mathrm{ml}$ & $0.1 \mathrm{ml}$ & $\pm 0.15 \mathrm{ml}$ & $\pm 0.18 \mathrm{ml}$ \\
\hline$V_{\ell, r e f}$ & $24.7 \mathrm{ml}$ & $0.1 \mathrm{ml}$ & $\pm 0.15 \mathrm{ml}$ & $\pm 0.18 \mathrm{ml}$ \\
\hline
\end{tabular}

[1] $r_{e, i}, r_{h p}, r_{r o d}:$ http://ecatalog.mitutoyo.com/Dial-Calipers-Series-505-C1387.aspx

[2] $p_{\text {air }, i}:$ http://www.idcide.com/citydata/ct/storrs.htm (elevation of Storrs, CT)

[3] $T_{\text {air },}, T_{\text {air }}:$ http://www.ni.com/pdf/manuals/372499b.pdf (temperature accuracy/uncertainty)

[4] $\Delta p_{\text {air }}:$ http://www.sperdirect.com/mas_assets/manuals/840065-i.pdf (meter resolution \& accuracy)

[5] $m_{f}$ : Mettler Toledo XS10001M Scale (mass resolution \& accuracy) 
Table 1 . Thermophysical properties at $T=301 \mathrm{~K}$.

\begin{tabular}{|c|c|c|c|c|c|}
\hline & PCM & HP working fluid & HP or Rod & Foil & Enclosure \\
\hline Material & $\begin{array}{c}\text { n-Octadecane } \\
{[26]}\end{array}$ & $\begin{array}{l}\text { Water } \\
{[20]}\end{array}$ & $\begin{array}{c}\text { Copper } \\
{[35]}\end{array}$ & $\begin{array}{c}\text { Aluminum } \\
{[35]}\end{array}$ & $\begin{array}{c}\text { Acrylic } \\
{[36]}\end{array}$ \\
\hline Density, $\rho\left(\mathrm{kg} / \mathrm{m}^{3}\right)$ & $\begin{array}{l}770 \text { (liquid) } \\
800 \text { (solid) }\end{array}$ & 996.6 (liquid) & 8933 & 2702 & 1150 \\
\hline Thermal conductivity, $k(\mathrm{~W} / \mathrm{m} \cdot \mathrm{K})$ & $\begin{array}{c}0.148 \text { (liquid) } \\
0.358 \text { (solid) }\end{array}$ & $\begin{array}{c}0.6132 \text { (liquid) } \\
0.01932 \text { (vapor) }\end{array}$ & 401 & 237 & 0.2 \\
\hline Specific heat, $c_{p}(\mathrm{~J} / \mathrm{kg} \cdot \mathrm{K})$ & $\begin{array}{c}2160 \text { (liquid) } \\
1912 \text { (solid) }\end{array}$ & $\begin{array}{l}4181 \text { (liquid) } \\
1882 \text { (vapor) }\end{array}$ & 385 & 903 & 1470 \\
\hline Viscosity, $\mu(\mathrm{Pa} \cdot \mathrm{s})$ & $3.09 \times 10^{-3}$ & $\begin{array}{l}8614 \times 10^{-7} \\
\text { (liquid) } \\
91.74 \times 10^{-7} \\
\text { (vapor) }\end{array}$ & & & \\
\hline Latent heat, $h_{s l}$ or $h_{f g}(\mathrm{~kJ} / \mathrm{kg})$ & 243.5 & 2434.9 & & & \\
\hline Melting point, $T_{m}(\mathrm{~K})$ & 301 & & & & \\
\hline Vapor pressure, $p_{\text {sat }}(\mathrm{Pa})$ & & 4352 & & & \\
\hline Thermal expansion coefficient, $\beta\left(\mathrm{K}^{-1}\right)$ & $9 \times 10^{-4}$ & & & & \\
\hline
\end{tabular}


Table 2. Thermocouple locations, See Fig. 1.

\begin{tabular}{|r|c|l|}
\hline Thermocouple & $r$-coordinate $(\mathrm{mm})$ & $z$-coordinate $(\mathrm{mm})$ \\
\hline$T_{1}$ & 13 & 105 \\
\hline$T_{2}$ & 13 & 125 \\
\hline$T_{3}$ & 13 & 145 \\
\hline$T_{4}$ & 13 & 165 \\
\hline$T_{5}$ & 13 & 195 \\
\hline$T_{6}$ & -13 & 105 \\
\hline$T_{7}$ & -13 & 125 \\
\hline$T_{8}$ & -13 & 145 \\
\hline$T_{9}$ & -13 & 165 \\
\hline$T_{10}$ & -13 & 195 \\
\hline$T_{11}$ & 3 & 15 \\
\hline$T_{12}$ & 3 & 30 \\
\hline$T_{13}$ & 3 & 45 \\
\hline & & \\
\hline
\end{tabular}


Table 3. Effective thermophysical properties.

\begin{tabular}{|l|c|c|}
\hline & Region I, $\left(f_{f}=0.0121\right)$ & Region II $\left(f_{f}=0.0116\right)$ \\
\hline$\rho_{\text {eff }}\left(\mathrm{kg} / \mathrm{m}^{3}\right)$ & 793 (liquid) & 792 (liquid) \\
& 823 (solid) & 822 (solid) \\
\hline$c_{p, \text { eff }}(\mathrm{J} / \mathrm{kg} \cdot \mathrm{K})$ & 2109 (liquid) & 2110 (liquid) \\
& 1872 (solid) & 1873 (solid) \\
\hline$h_{\text {sl }, \text { eff }}(\mathrm{kJ} / \mathrm{kg})$ & 233.5 (liquid) & 233.9 (liquid) \\
& 233.8 (solid) & 234.2 (solid) \\
\hline$k_{\text {eff, },}(\mathrm{W} / \mathrm{m} \cdot \mathrm{K})$ & 3.01 (liquid) & 0.188 (liquid) \\
& 3.21 (solid) & 0.454 (solid) \\
\hline$k_{\text {eff, }, z}(\mathrm{~W} / \mathrm{m} \cdot \mathrm{K})$ & 0.149 (liquid) & 0.149 (liquid) \\
& 0.362 (solid) & 0.362 (solid) \\
\hline
\end{tabular}




\section{Figure Captions}

Fig. 1. Experimental setup.

Fig. 2. Test cell geometry: (a) computational domain, (b) PCM sub-regions.

Fig. 3. Temperatures within the PCM (left) and on the HP evaporator section (right) during melting with $L_{t}=90 \mathrm{~mm}, L_{b}=55 \mathrm{~mm}$. (a) HP, (b) HP-Foil $\left(f_{f}=0.0121\right)$.

Fig. 4. Predicted temperature distributions for the conditions of Fig. 3. Results are for (a) HP-Foil $\left(f_{\ell}=0.0121\right)$, (b) HP, and (c) Rod. Isotherms are shown at intervals of $1 \mathrm{~K}$ over the range $28^{\circ} \mathrm{C} \leq T \leq 45^{\circ} \mathrm{C}$ for all cases.

Fig. 5. Melting liquid fraction (left) and effectiveness (right) histories for $T_{h t f}-T_{m}=17^{\circ} \mathrm{C}$ and $f_{f}=$ 0.0121: (a) $L_{t}=90 \mathrm{~mm}, L_{b}=55 \mathrm{~mm}$ (b) $L_{t}=80 \mathrm{~mm}, L_{b}=65 \mathrm{~mm}$, (c) $L_{t}=72 \mathrm{~mm}, L_{b}=73 \mathrm{~mm}$.

Fig. 6. Solidification liquid fraction (left) and effectiveness (right) histories for $T_{m}-T_{h f}=17^{\circ} \mathrm{C}$ and $f_{f}=0.0121:$ (a) $L_{t}=90 \mathrm{~mm}, L_{b}=55 \mathrm{~mm}$ (b) $L_{t}=80 \mathrm{~mm}, L_{b}=65 \mathrm{~mm}$, (c) $L_{t}=72 \mathrm{~mm}, L_{b}=73$ $\mathrm{mm}$.

Fig. 7. Liquid fraction histories for the HP-Foil configuration $\left(L_{t}=90 \mathrm{~mm}, L_{b}=55 \mathrm{~mm}, f_{f}=\right.$ 0.0121 ), (a) melting for various $T_{h f}-T_{m}$ (b) solidification for various $T_{m}-T_{h f}$.

Fig. A.1. Conceptual melting process: (a) initial (100\% solid), (b) solid and liquid PCM, (c) final (100\% liquid). 


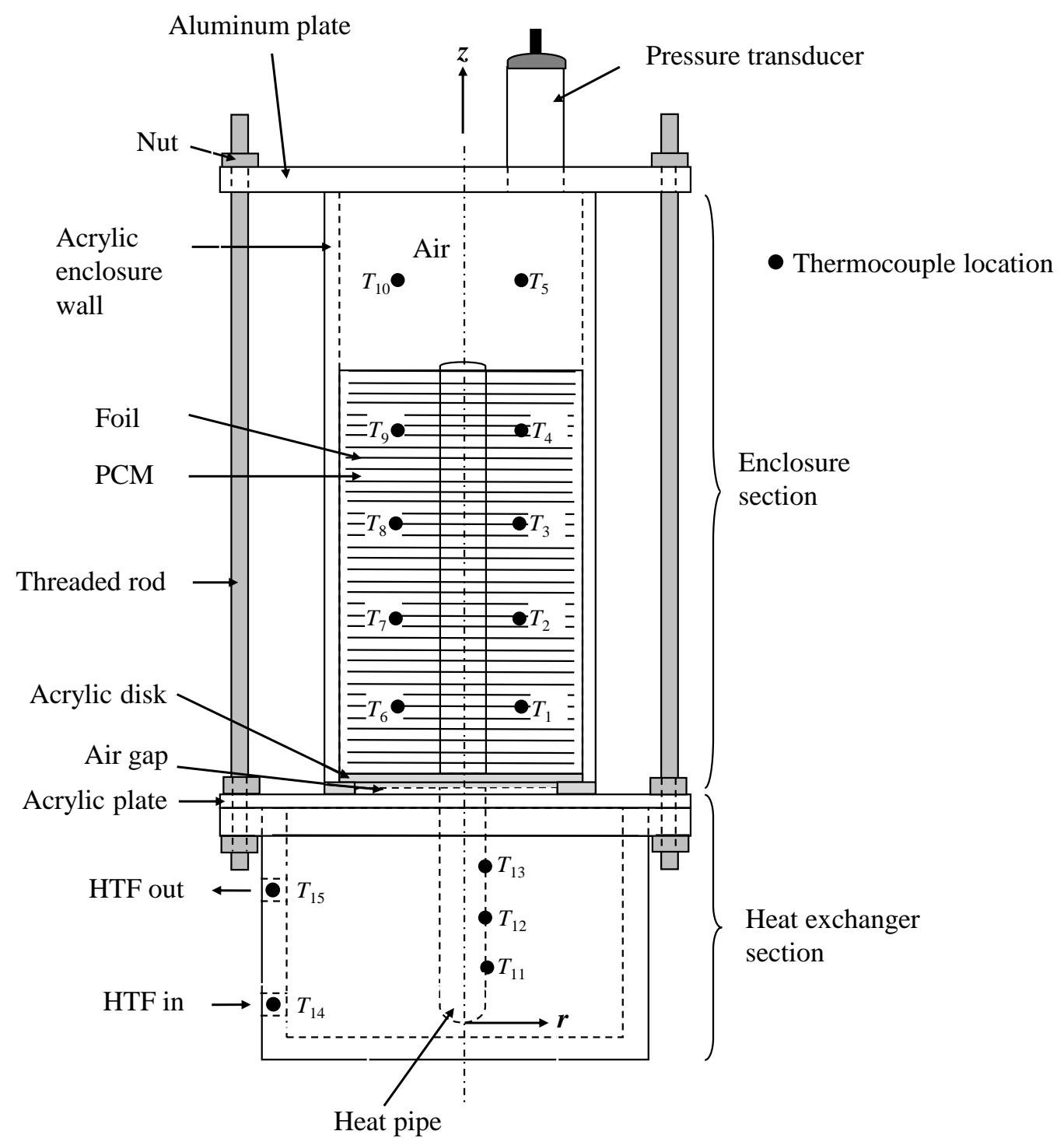

Fig. 1. Experimental setup. 


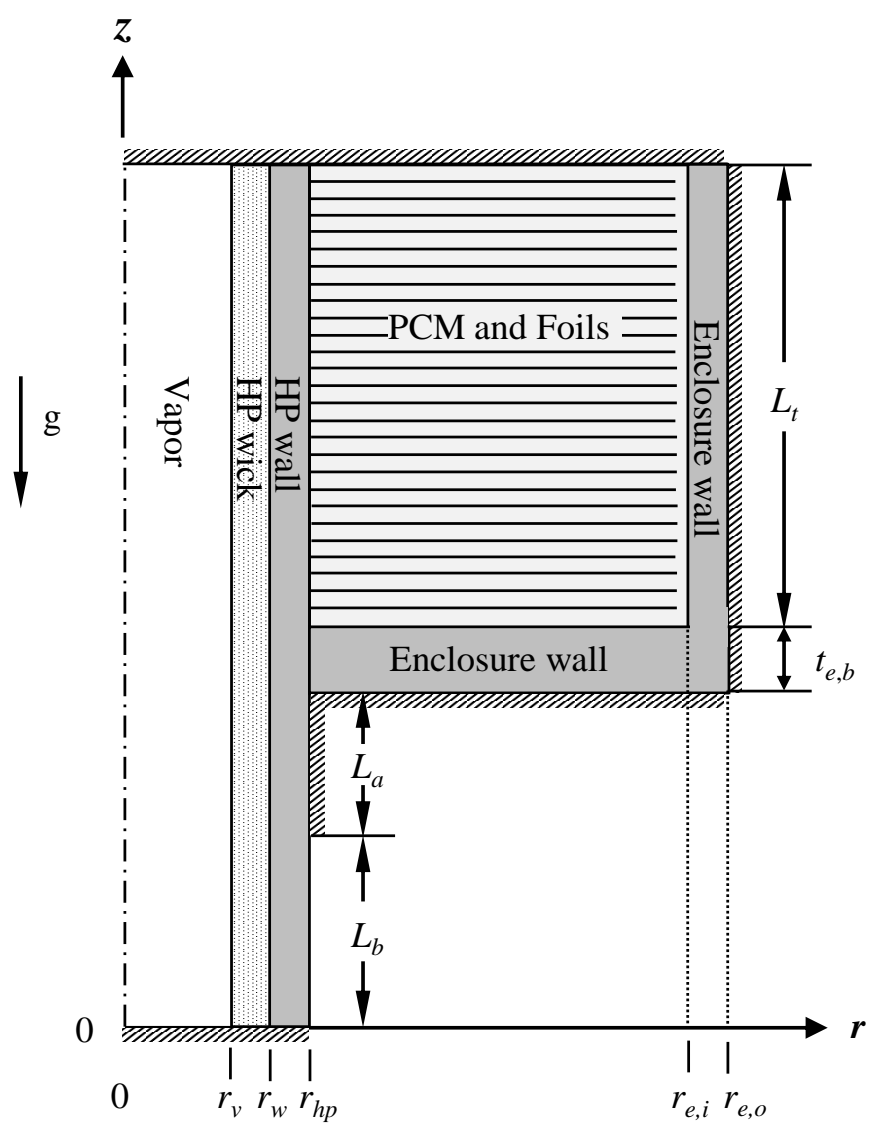

(a)

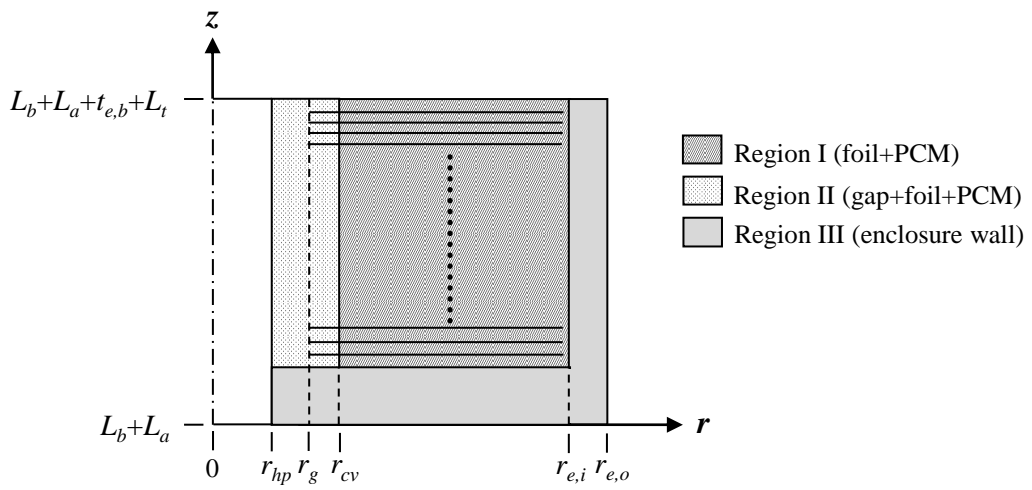

(b)

Fig. 2. Test cell geometry: (a) computational domain, (b) PCM sub-regions. 

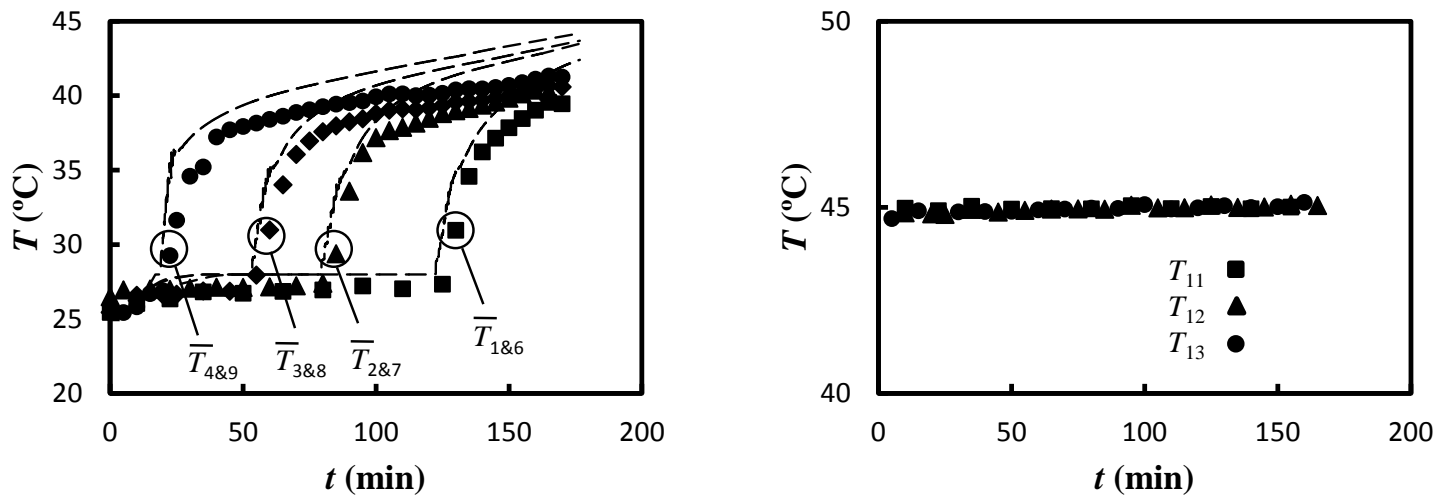

(a)
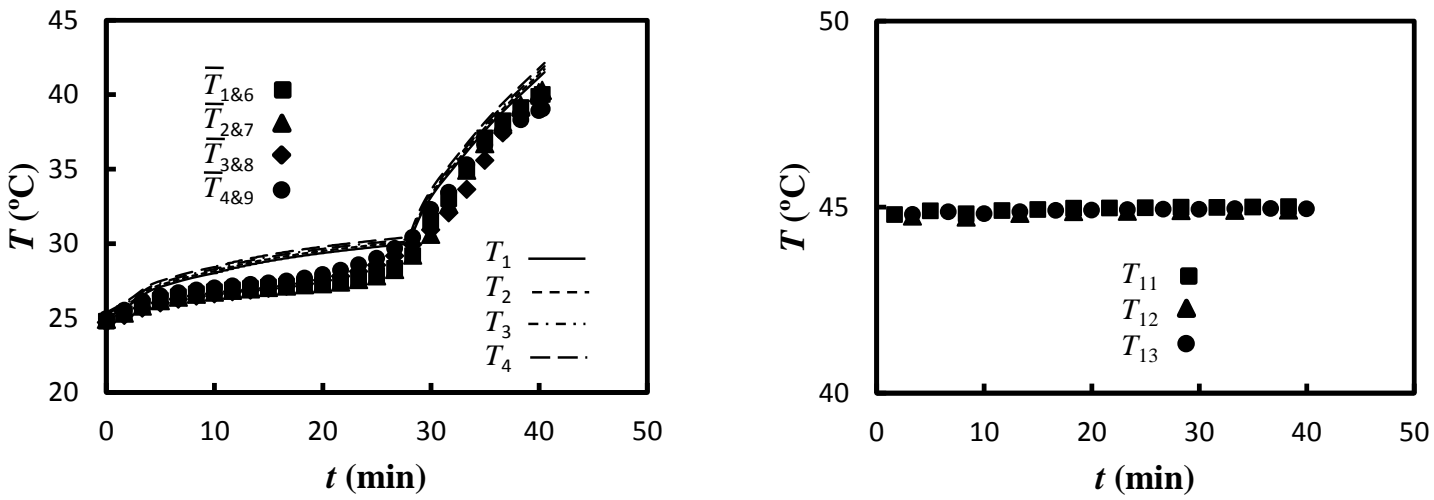

(b)

Fig. 3. Temperatures within the PCM (left) and on the HP evaporator section (right) during melting with $L_{t}=90 \mathrm{~mm}, L_{b}=55 \mathrm{~mm}$. (a) HP, (b) HP-Foil $\left(f_{f}=0.0121\right)$. 

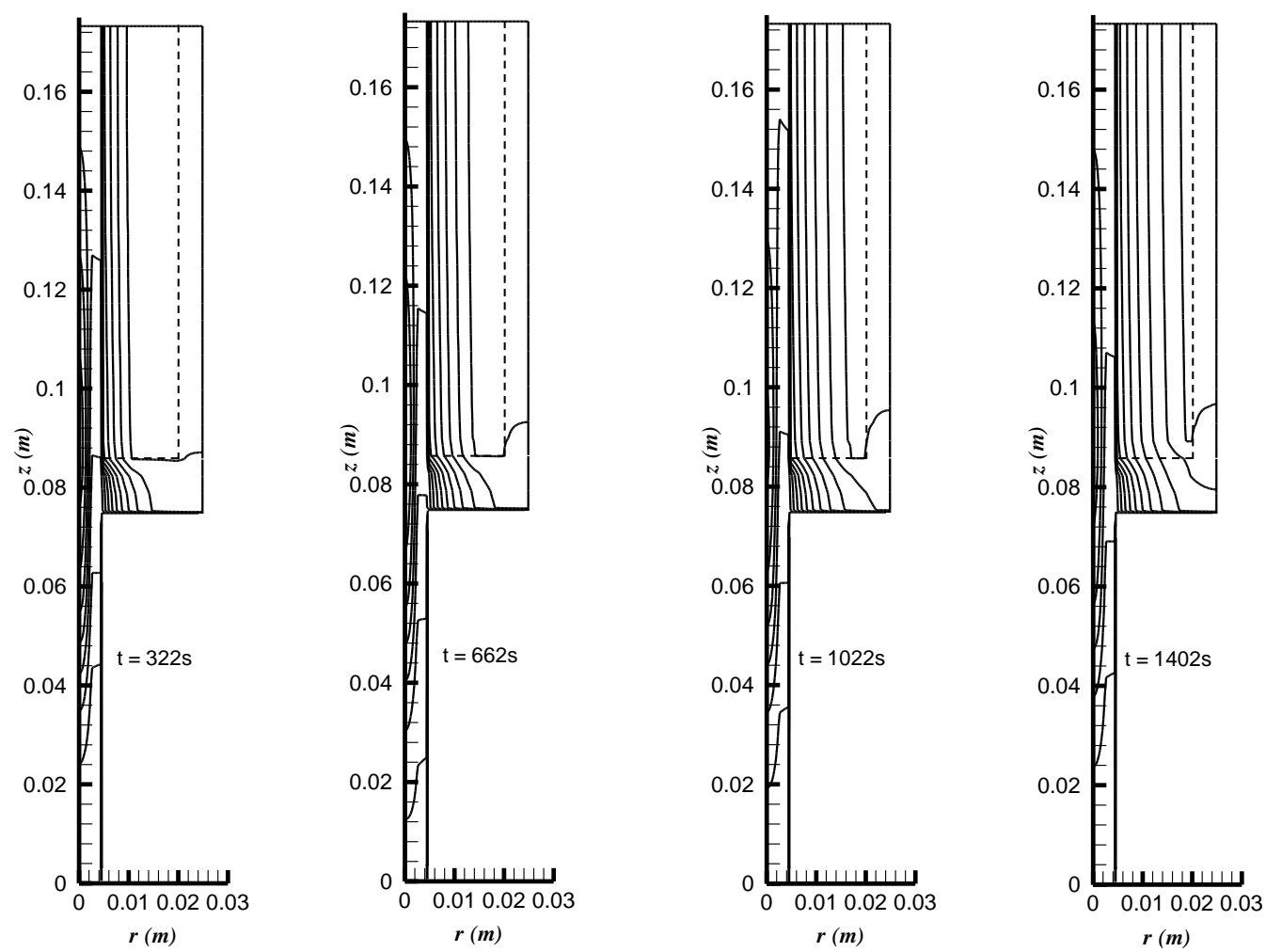

(a)
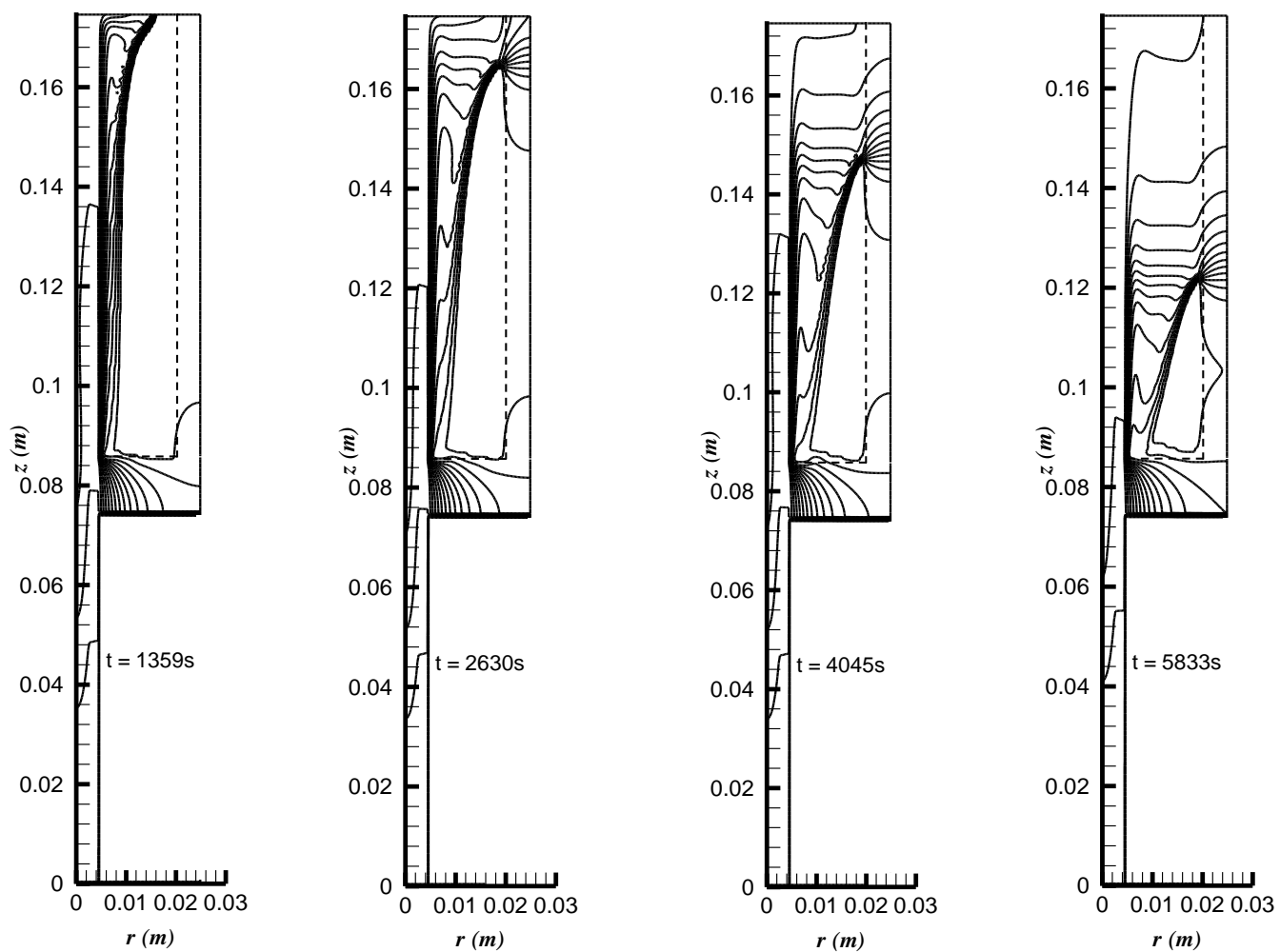

(b) 

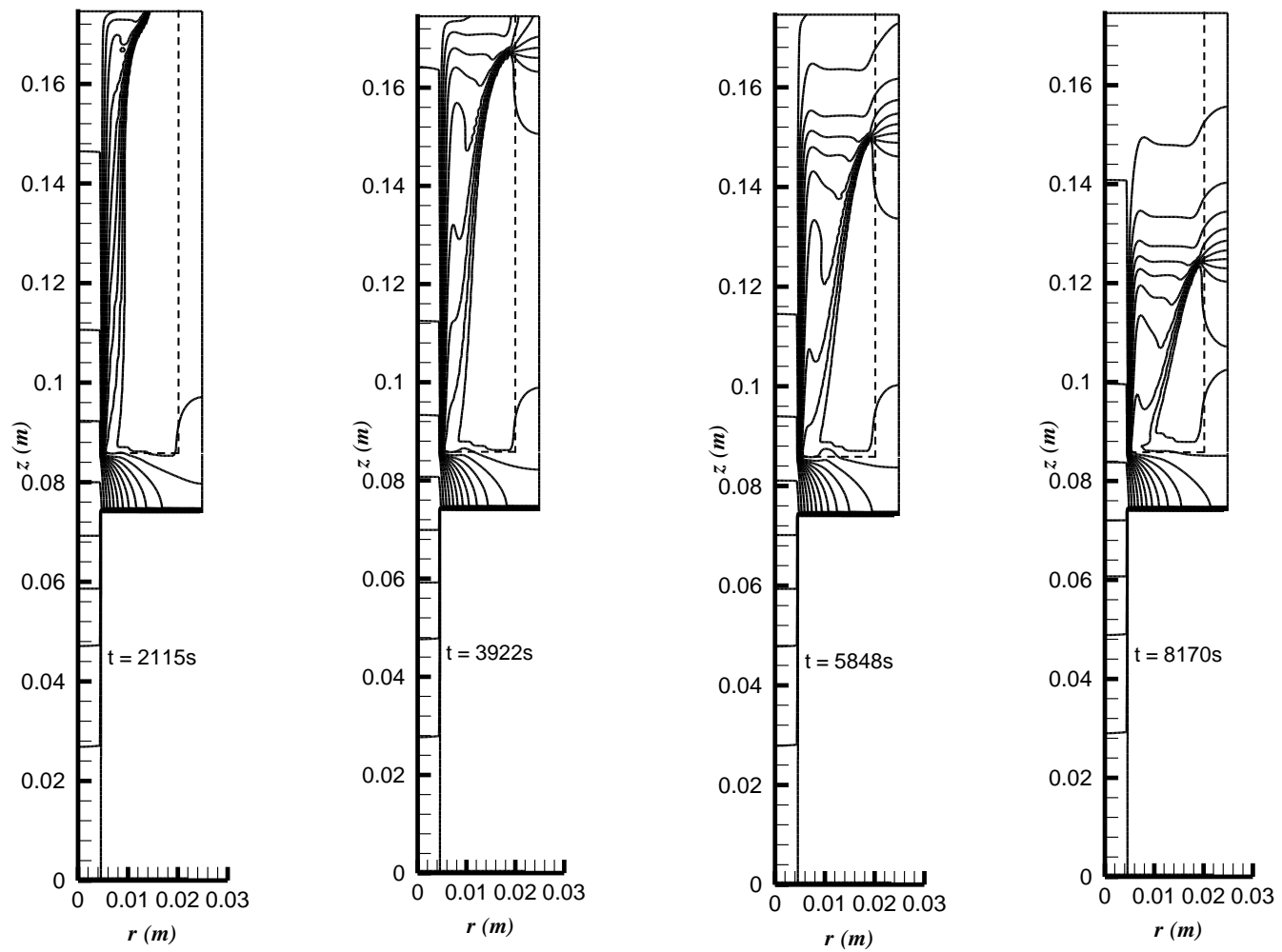

(c)

Fig. 4. Predicted temperature distributions for the conditions of Fig. 3. Results are for (a) HP-Foil $\left(f_{\ell}=0.0121\right)$, (b) HP, and (c) Rod. Isotherms are shown at intervals of $1 \mathrm{~K}$ over the range $28^{\circ} \mathrm{C} \leq T \leq 45^{\circ} \mathrm{C}$ for all cases. 

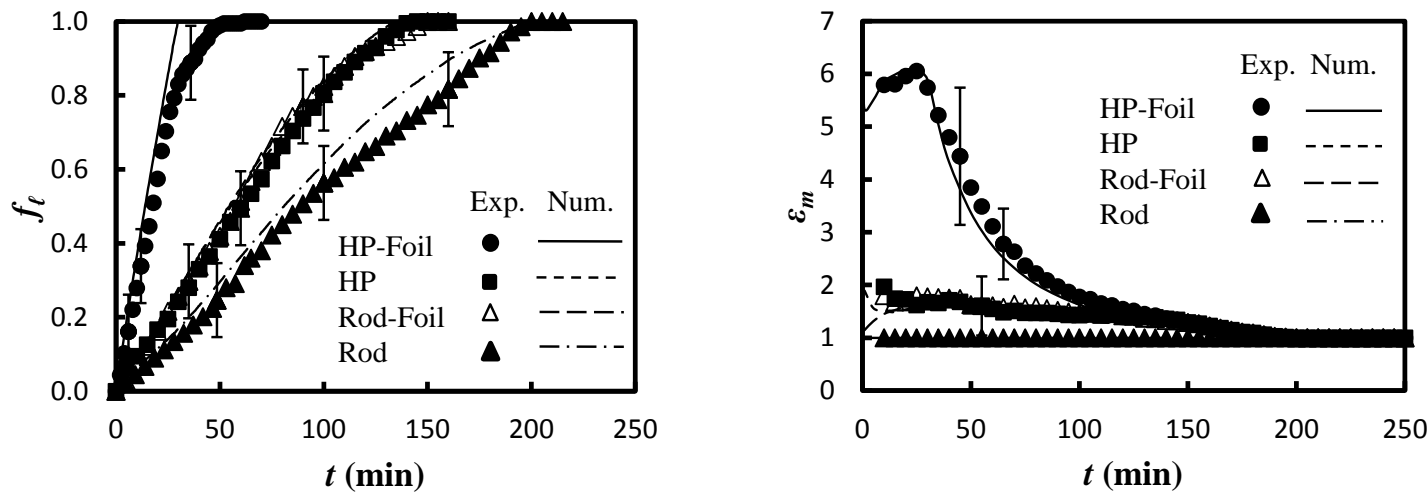

(a)
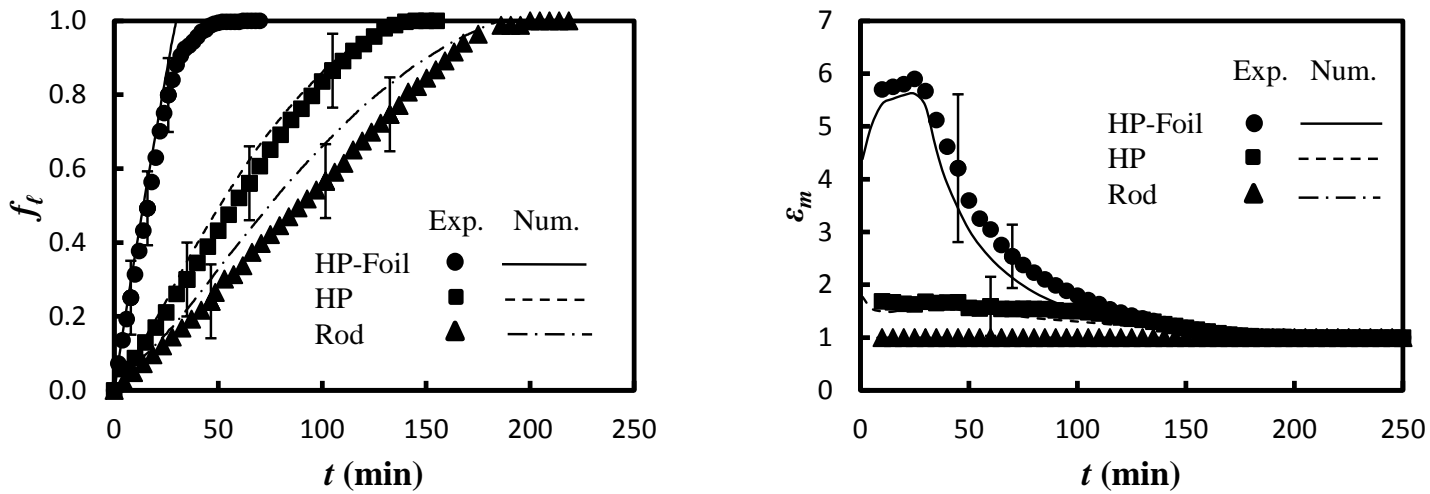

(b)
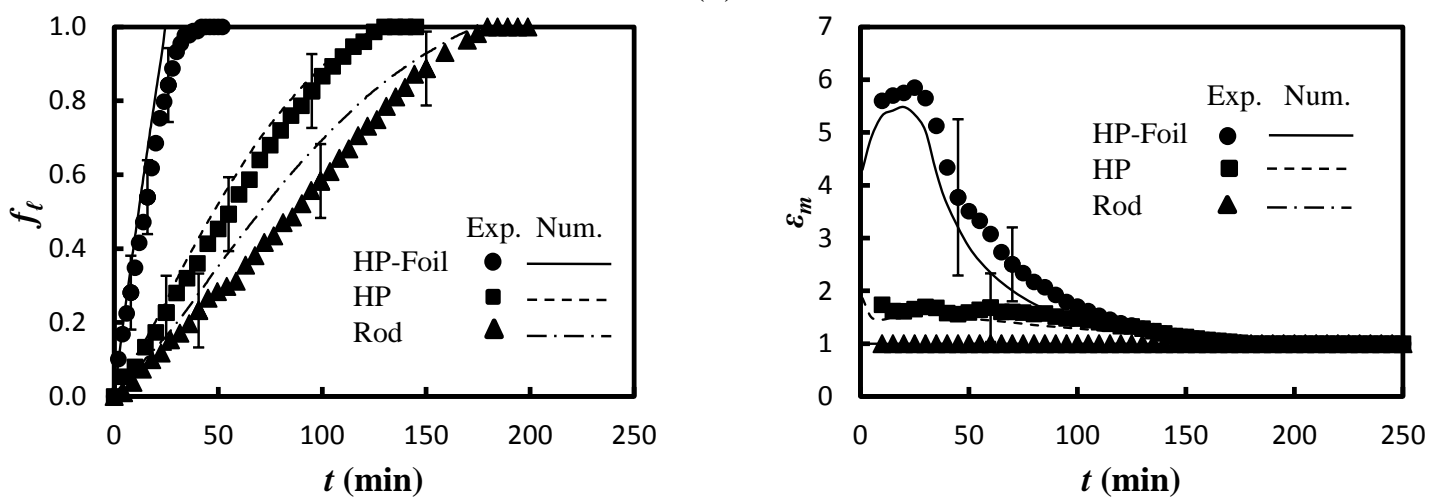

(c)

Fig. 5. Melting liquid fraction (left) and effectiveness (right) histories for $T_{h f f}-T_{m}=17^{\circ} \mathrm{C}$ and $f_{f}=$ 0.0121: (a) $L_{t}=90 \mathrm{~mm}, L_{b}=55 \mathrm{~mm}$ (b) $L_{t}=80 \mathrm{~mm}, L_{b}=65 \mathrm{~mm}$, (c) $L_{t}=72 \mathrm{~mm}, L_{b}=73 \mathrm{~mm}$. 

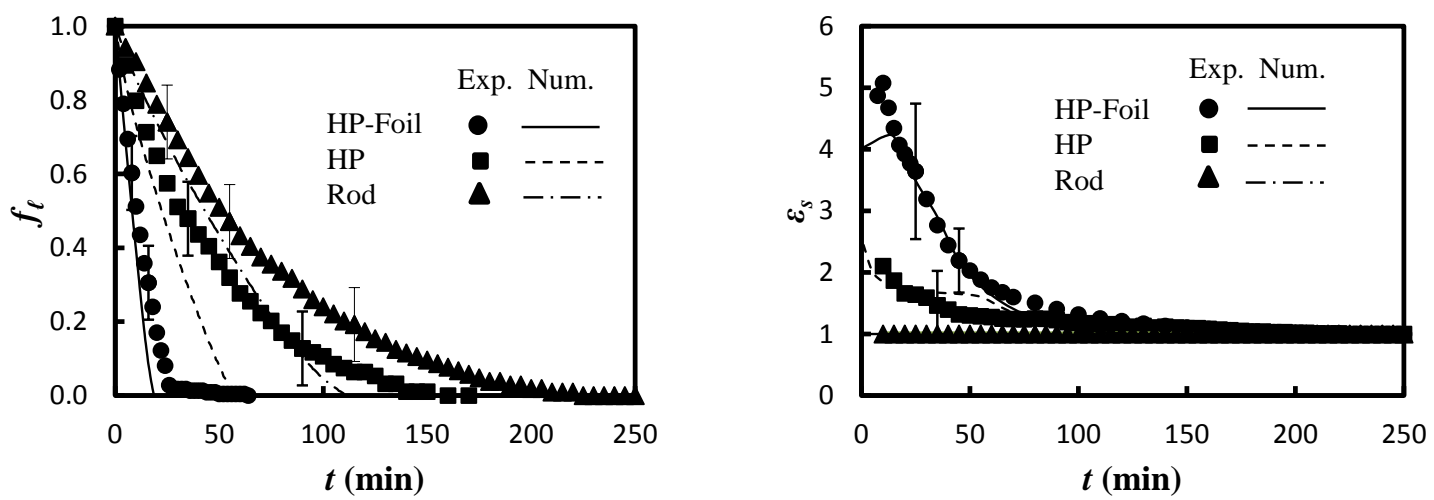

(a)
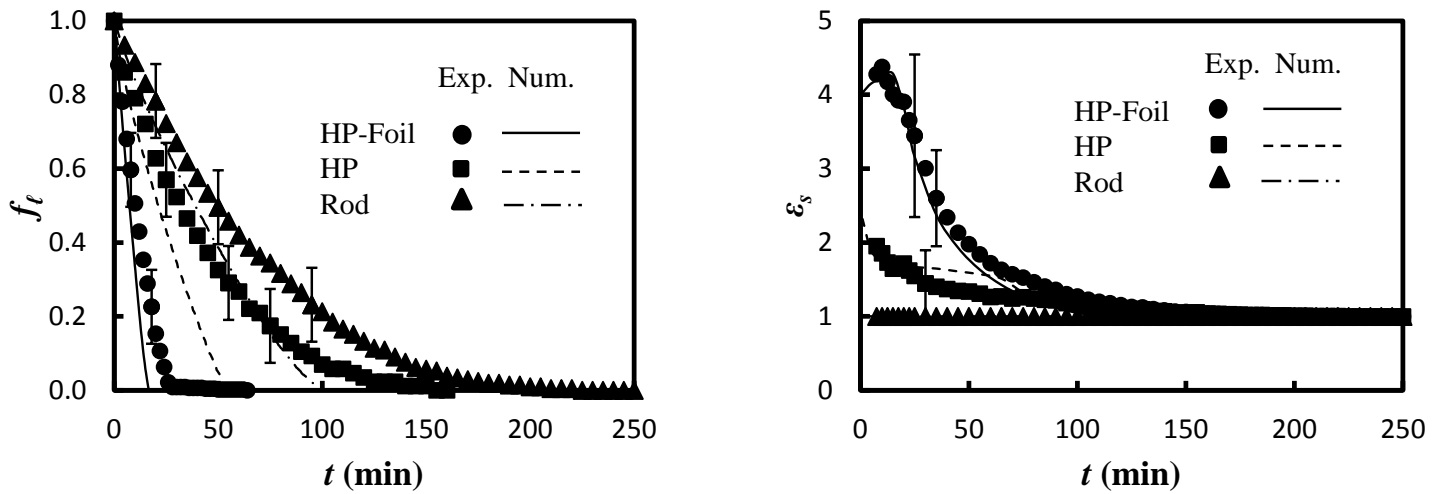

(b)
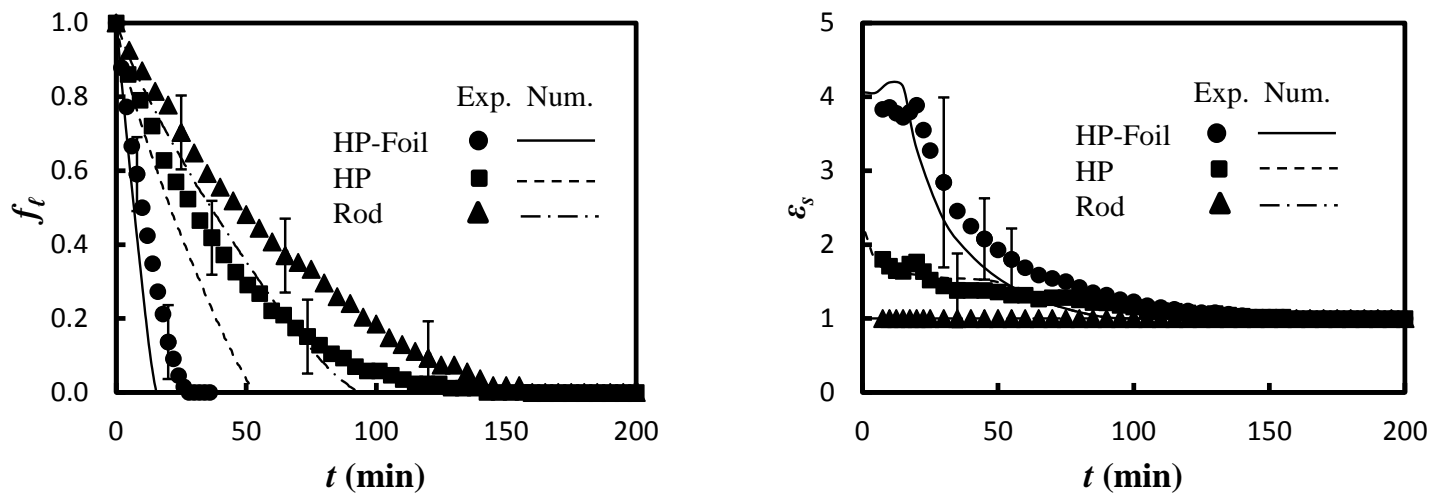

(c)

Fig. 6. Solidification liquid fraction (left) and effectiveness (right) histories for $T_{m}-T_{h t f}=17^{\circ} \mathrm{C}$ and $f_{f}=0.0121:$ (a) $L_{t}=90 \mathrm{~mm}, L_{b}=55 \mathrm{~mm}$ (b) $L_{t}=80 \mathrm{~mm}, L_{b}=65 \mathrm{~mm}$, (c) $L_{t}=72 \mathrm{~mm}, L_{b}=73$ $\mathrm{mm}$. 


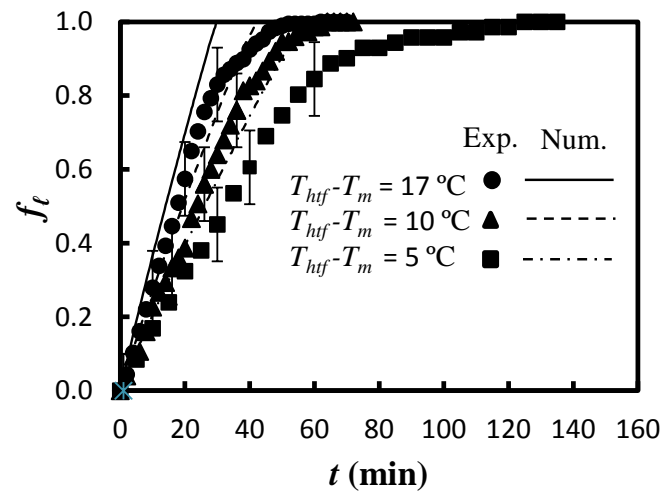

(a)

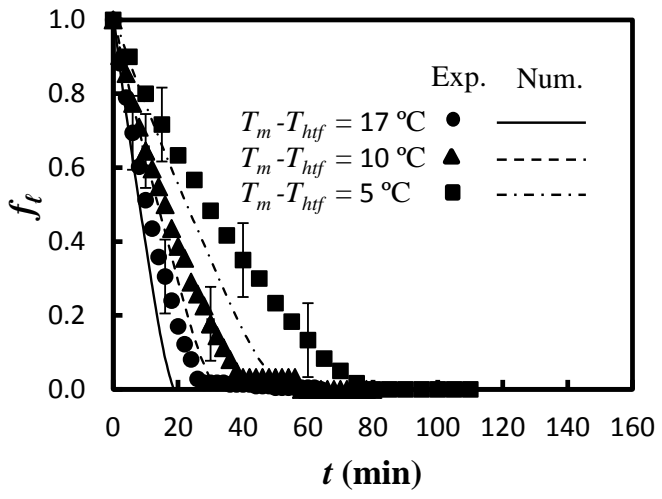

(b)

Fig. 7. Liquid fraction histories for the HP-Foil configuration $\left(L_{t}=90 \mathrm{~mm}, L_{b}=55 \mathrm{~mm}, f_{f}=\right.$ 0.0121 ), (a) melting for various $T_{h t f}-T_{m}$ (b) solidification for various $T_{m}-T_{h t}$.

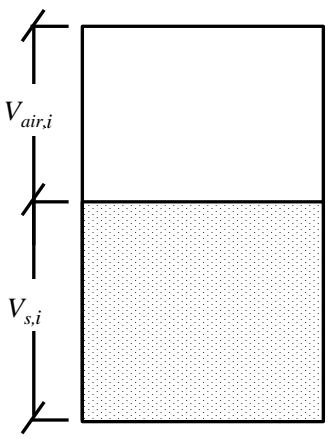

(a)

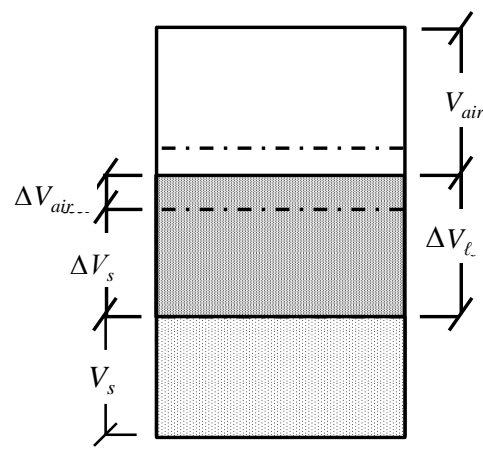

(b)

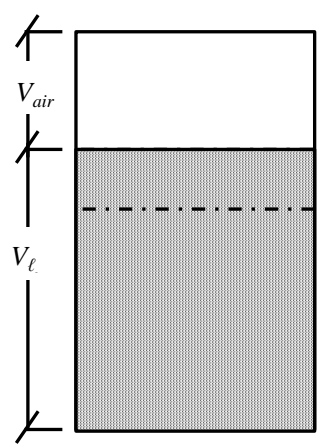

(c)

Fig. A.1. Conceptual melting process: (a) initial (100\% solid), (b) solid and liquid PCM, (c) final (100\% liquid). 